\title{
Causes of the 2011-14 California Drought*
}

\author{
Richard SeAger, ${ }^{+}$Martin Hoerling, ${ }^{\#}$ Siegfried Schubert,${ }^{@}$ Hailan Wang, \\ BRADFIELD LYON, ${ }^{\&}$ ARUN KUMAR, $* *$ JENNIFER NAKAMURA, ${ }^{+}$AND \\ NAOMI HENDERSON ${ }^{+}$ \\ ${ }^{+}$Lamont-Doherty Earth Observatory, Columbia University, Palisades, New York

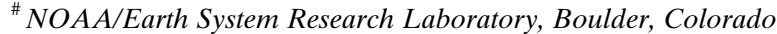 \\ ${ }^{\circledR}$ NASA Goddard Space Flight Center, Greenbelt, Maryland \\ ${ }^{\&}$ International Research Institute for Climate and Society, Columbia University, Palisades, New York \\ ** NOAA/Climate Prediction Center, College Park, Maryland
}

(Manuscript received 19 December 2014, in final form 25 June 2015)

\begin{abstract}
The causes of the California drought during November-April winters of 2011/12-2013/14 are analyzed using observations and ensemble simulations with seven atmosphere models forced by observed SSTs. Historically, dry California winters are most commonly associated with a ridge off the west coast but no obvious SST forcing. Wet winters are most commonly associated with a trough off the west coast and an El Niño event. These attributes of dry and wet winters are captured by many of the seven models. According to the models, SST forcing can explain up to a third of California winter precipitation variance. SST forcing was key to sustaining a high pressure ridge over the west coast and suppressing precipitation during the three winters. In 2011/12 this was a response to a La Niña event, whereas in 2012/13 and 2013/14 it appears related to a warm west-cool east tropical Pacific SST pattern. All models contain a mode of variability linking such tropical Pacific SST anomalies to a wave train with a ridge off the North American west coast. This mode explains less variance than ENSO and Pacific decadal variability, and its importance in 2012/13 and 2013/14 was unusual. The models from phase 5 of CMIP (CMIP5) project rising greenhouse gases to cause changes in California all-winter precipitation that are very small compared to recent drought anomalies. However, a long-term warming trend likely contributed to surface moisture deficits during the drought. As such, the precipitation deficit during the drought was dominated by natural variability, a conclusion framed by discussion of differences between observed and modeled tropical SST trends.
\end{abstract}

\section{Introduction}

The November-April winter precipitation season in 2013/14 was, according to the National Oceanic and Atmospheric Administration (NOAA) Climate Division data, the sixth driest for the state of California as a whole that has occurred since records begin in 1895 . The previous two winter precipitation seasons were also dry, and the same data show that the 2011-14 three-winter average precipitation for California was the second driest that

* Lamont Doherty Earth Observatory Contribution Number 7925.

Corresponding author address: Richard Seager, Lamont-Doherty Earth Observatory, Columbia University, 61 Route 9W., Palisades, NY 10964.

E-mail: seager@ldeo.columbia.edu has occurred since 1895 (Fig. 1). The Climate Division data (Vose et al. 2014) also show that the all-California November 2013 through April 2014 winter and the 2011-14 three-winter average were the warmest on record (Fig. 1), adding further stress to surface moisture by increased evaporative loss and water demand and reduced snowpack. The 2013/14 winter, coming as the third year of a major drought, left California water resources in a severely depleted state. In April 2014, Governor Jerry Brown issued the second emergency drought proclamation in two months. In November 2014, according to the California Department of Water Resources (2015), the statewide water storage was about $56 \%$ of the average for the time of year. California is the nation's leading agricultural producer and one of the major agricultural regions of the world. Reductions in precipitation and water available for irrigation are being largely offset by increased groundwater pumping, an 

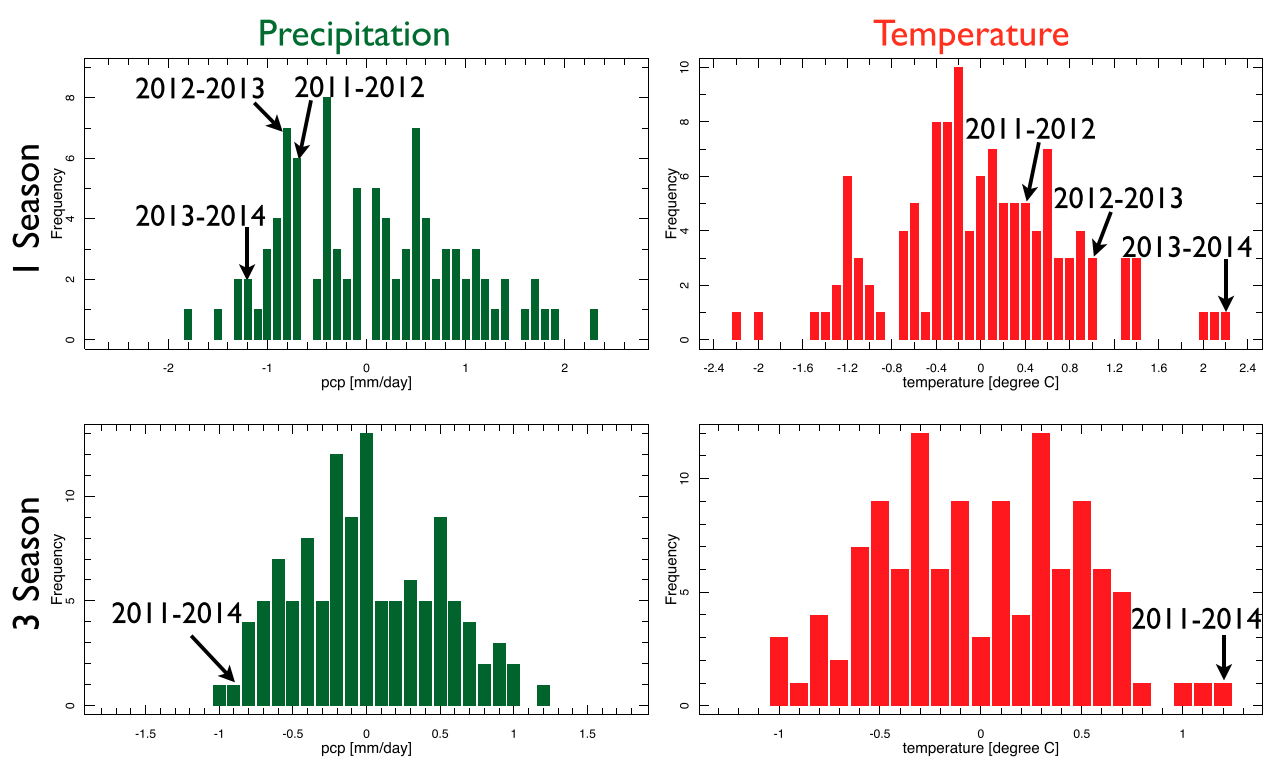

FIG. 1. Histograms of (top) 1- and (bottom) 3-yr average winter all-California (left) precipitation $\left(\mathrm{mm} \mathrm{day}^{-1}\right.$ ) and (right) surface air temperature $\left({ }^{\circ} \mathrm{C}\right)$ from $1895 / 96$ to $2013 / 14$ given in the NOAA Climate Division data. (top) The last 3 years and (bottom) the last 3-yr average are marked.

unsustainable situation at least in the southern Central Valley (e.g., Scanlon et al. 2012; see also Famiglietti and Rodell 2013; Amos et al. 2014; Borsa et al. 2014), and the 2014 year of drought has cost California $\$ 2.2$ billion in damages and 17000 agricultural jobs (Howitt et al. 2014).

The ongoing California drought lies within a largerscale context whereby, at any one time, drought has been afflicting much of southwestern North America since the end of the 1990s (Seager 2007; Weiss et al. 2009; Hoerling et al. 2010; Cayan et al. 2010; Seager and Vecchi 2010; Seager and Hoerling 2014) and shortly after a devastating 1-yr drought struck the U.S. Great Plains and Midwest (Hoerling et al. 2014). Concern for the future of southwestern water is only intensified by projections by climate models. These indicate that for much of southwestern North America, a combination of declining winter precipitation (except central to Northern California) and rising temperatures will reduce water availability in coming decades as a consequence of rising greenhouse gases (GHGs; Seager et al. 2007, 2013; Maloney et al. 2014; Vano et al. 2014). During the last winter's drought there was much discussion, up to the level of the President, as to whether it was caused or made worse by human-driven climate change.

Three recent papers examined the potential role for climate change in the California drought of the last two winters. The comparison of these three studies, employing different methods and models, found no substantial effect of human-induced climate change on the severe precipitation deficits over California (Herring et al. 2014). One of the studies (Swain et al. 2014) concluded that global warming was increasing the likelihood of extreme high pressure over an index region of the North Pacific similar to that observed during the recent drought. Wang and Schubert (2014) found some evidence of forcing by sea surface temperature (SST) anomalies of a dry tendency for winter 2012/13 but no evidence of an influence from the long-term SST trend. Their result largely agreed with a separate analysis by Funk et al. (2014) using a different atmospheric model. These results are good motivation for the comprehensive analysis of the 2011-14 California drought presented here.

Drought is nothing new to California. Figure 2 shows the winter half-year precipitation history for all of California. The driest winter was 1976/77, for example, and there was an extended dry period in the 1920s and

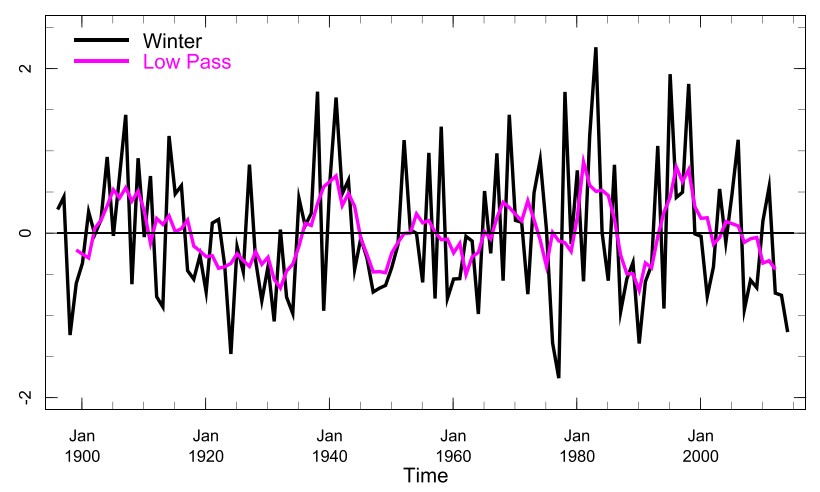

FIG. 2. Time series of all-California November-April winter precipitation $\left(\mathrm{mm} \mathrm{day}^{-1}\right)$ for 1895-2014 and the same after lowpass filtering with a 6-yr running average. 
1930s (Mirchi et al. 2013), which included the second driest winter of 1923/24. The driest 3-yr period was 197477, which included the driest winter and 1975/76, the fourth driest winter. There have also been extended wet periods, including one in the mid-1990s. This preceded a period of steadily declining precipitation up to and including the 2011-14 drought, and part of the explanation of the recent drought will involve explaining the decline in winter precipitation over the recent decades. However, over the entire 120 years of record, there is no clear trend toward wetter or drier conditions. While the precipitation decrease was the essential cause of the recent drought, the last winter in California was also very warm, reducing soil moisture and streamflow beyond that owing to the precipitation drop alone.

Over the last few decades since the pioneering work of Ropelewski and Halpert (1986), it has become clear that SST variability exerts a strong control over precipitation across much of southwestern North America. In a recent review, Seager and Hoerling (2014) claim that as much as a quarter of the interannual variability of precipitation for southwestern North America as a whole is explained in terms of an atmospheric response to tropical Pacific SST anomalies with La Niña (El Niño) events tending to make it dry (wet). These tropical Pacific-driven precipitation teleconnections do include California during winter (e.g., Mason and Goddard 2001; Seager et al. 2014a) but, according to the same analysis, SST-driven variability tends to account for at most a quarter of the interannual precipitation variance in California. This suggests that the precipitation history of California will be heavily influenced by random atmospheric variability.

So what did cause the drought? What were the relative contributions of SST forcing, human-driven climate change, and random atmospheric variability? Could this drought have been predicted? Is the 2011-14 event akin to prior California droughts or different? These are among the questions we attempt to address using analyses of observations, simulations with atmosphere models forced by observed SSTs through April 2014, and coupled atmosphere-ocean models forced by known past and estimated future changes in radiative forcing. By taking a long-term perspective on the meteorological causes of California drought, as well as considering projections of radiatively driven climate change, we hope to provide a considerably improved understanding of the causes and predictability of California drought in general.

In section 2 we detail the observational data and models used. Section 3 describes the observed atmosphere-ocean state during the past three winters, and section 4 examines the multimodel ensemble mean response to imposed SST anomalies for these winters. Section 5 then discusses the more general causes of wet and dry winters in California.
Section 6 examines in more detail the model simulations of the past three winters. Section 7 examines the role of SST forcing for the recent drought, and section 8 compares the long-term history of California precipitation with that simulated by SST-forced models. Section 9 analyzes the temperature anomalies during the drought. Section 10 assesses the contribution of human-induced climate change to the recent drought. Conclusions and discussion are offered in section 11.

\section{Observational data and model simulations}

The precipitation data used are the Climate Division data from NOAA chosen because they extend up to the most recent month, begin in 1895, and hence allow the recent winters to be placed in long-term context (Vose et al. 2014; http://iridl.ldeo.columbia.edu/SOURCES/ NOAA/.NCDC/.CIRS/.nClimDiv/.v1/.pcp/). The seven California climate divisions were formed into an areaweighted, all-California average. Circulation anomalies are diagnosed using the National Centers for Environmental Prediction-National Center for Atmospheric Research (NCEP-NCAR) reanalysis extending from 1949 to April 2014 (Kalnay et al. 1996; Kistler et al. 2001). SST data for the observational analysis are from the NCEPNCAR reanalysis. The model simulations to be described below are an ensemble of opportunity of various models that have been forced by global historical SSTs up through the past winter and with multiple ensemble members. The model data analyzed in this paper are available online (http://dolphy.ldeo.columbia.edu:81/SOURCES/.DTF/).

1) A 16-member ensemble with the NCAR Community Climate Model, version 3 (CCM3; Kiehl et al. 1998), that covers January 1856-April 2014. The model was run at spectral truncation T42 $\left(\sim 2.8^{\circ} \times 2.8^{\circ}\right)$ resolution with 18 vertical levels (L18). Sea ice was held at climatological values. The SST forcing combines the Kaplan et al. (1998) SST globally from 1856 to 1870 , and in the tropical Pacific Ocean $\left(20^{\circ} \mathrm{N}-20^{\circ} \mathrm{S}\right)$ through 2009 , and the Hadley Centre SST (Rayner et al. 2003) outside of the tropical Pacific from 1871 through 2009. The Hadley Centre data were used globally from 2010 to 2014.

2) A 24-member ensemble with the ECHAM 4.5 model (Roeckner et al. 1996) from January 1950 through February 2014 forced by the NOAA ERSST dataset for SST (Smith and Reynolds 2004) and with sea ice held fixed at climatological values from the same data. Trace gases were held fixed at 1990 values. Model resolution was T42 $\left(\sim 2.8^{\circ} \times 2.8^{\circ}\right)$ with 19 vertical levels (L19).

3) A 20-member ensemble with the ECHAM5 model (Roeckner et al. 2003) from January 1979 through April 2014 forced by the Hurrell et al. (2008) SST and sea ice data, as recommended for use in phase 5 of the Coupled 
TABLE 1. Name, contributing institution, ensemble size, resolution, ocean and trace gas boundary conditions, and time period of simulation for the seven atmosphere models used in this study. (Expansions of acronyms are available at http://www.ametsoc.org/ PubsAcronymList.)

\begin{tabular}{llclllr}
\hline \hline \multicolumn{1}{c}{ Model } & Contributor & Ensemble & \multicolumn{1}{c}{ Resolution } & \multicolumn{1}{c}{ SST, sea ice } & Trace gases & Time period \\
\hline CCM3 & LDEO & 16 & T42L18 & Hadley Centre, ice fixed & Fixed & $1856-2014$ \\
ECHAM4.5 & IRI & 24 & T42L19 & ERSST, ice fixed & Fixed & $1950-2014$ \\
ECHAM5 & NOAA/ESRL & 20 & T159L31 & Hurrell et al. (2008) & Varying GHGs & $1979-2014$ \\
GEOS-5 & NASA GSFC & 12 & $1^{\circ} \times 1^{\circ}$, L72 & Hurrell et al. (2008) & Varying & $1871-2014$ \\
ESRL GFSv2 & NOAA/ESRL & 50 & T126L64 & Hurrell et al. (2008) & Varying CO $_{2}$ & $1979-2014$ \\
NCEP GFSv2 & NOAA/CPC & 18 & T126L64 & Hurrell et al. (2008) & Varying CO $_{2}$ & $1957-2014$ \\
CAM4 & NOAA/ESRL & 20 & $0.94^{\circ} \times 125^{\circ}$, L26 & Hurrell et al. (2008) & Varying $^{1979-2014}$ \\
\hline
\end{tabular}

Model Intercomparison Project (CMIP5), simulations, and time-varying GHGs, using the RCP6.0 scenario after 2005. The resolution was T159 spectral truncation $\left(\sim 0.75^{\circ} \times 0.75^{\circ}\right)$ with 31 vertical levels (L31).

4) A 12-member ensemble with the National Aeronautics and Space Administration (NASA) Goddard Earth Observing System Model, version 5 (GEOS-5; Rienecker et al. 2008; Molod et al. 2012; Schubert et al. 2014) from January 1871 to April 2014 forced by observed SSTs and sea ice from Hurrell et al. (2008) up through March 2012 and the NOAA Optimum Interpolation (OI) data since and with time-varying GHGs. Model resolution was $1^{\circ}$ latitude $\times 1^{\circ}$ longitude with 72 hybrid-sigma levels in the vertical (L72).

5) A 50-member ensemble of the NCEP Global Forecast System (GFS, the atmosphere component of the Climate Forecast System), version 2 (GFSv2), model in the version run by the NOAA/Earth System Research Laboratory (ESRL GFSv2), extending from January 1979 to April 2014. The model was run at spectral truncation $\mathrm{T} 126\left(\sim 1^{\circ} \times 1^{\circ}\right)$ resolution with 64 vertical levels (L64). The model was forced by observed SST and sea ice from the Hurrell et al. (2008) data and had time-varying $\mathrm{CO}_{2}$ with other radiative forcings held fixed.

6) An 18-member ensemble of the GFSv2 with the version run by NCEP for January 1957-April 2014. The model was run at $\mathrm{T} 126\left(\sim 1^{\circ} \times 1^{\circ}\right)$ resolution with 64 vertical levels. The model was also forced by the Hurrell et al. (2008) SST and sea ice data and had timevarying $\mathrm{CO}_{2}$ with other radiative forcings fixed.

7) A 20-member ensemble with the NCAR Community Atmosphere Model, version 4 (CAM4), from January 1979 to April 2014 forced by SST and sea ice from the Hurrell et al. (2008) dataset and with timevarying GHGs using the RCP6.0 scenario after 2005. The resolution was $0.94^{\circ} \times 1.25^{\circ}$ with 26 vertical levels (L26).

Of these models, CCM3 and CAM4 are earlier and later generations of the NCAR atmosphere models with different dynamical cores and significantly different treatments of atmospheric physics. Similarly, ECHAM5 was a successor model to ECHAM4.5; both use a spectral formulation, but major changes were made to atmosphere and land surface physics. The GFSv2 and GEOS-5 models have their own separate lineages. The NCEP and ESRL versions of GFSv2 are almost the same model but small differences (as well as the use of different code compilers and computers) mean that they do simulate different climates. For more model information, see Table 1.

As a reality check, the seasonal cycles of all-California precipitation for observations, the seven model ensemble means, and the multimodel ensemble mean were computed. The observations and all the models have a June-September dry season, precipitation increasing from October to a December-February winter peak, followed by a decline to May. However, all the models except for ECHAM5 and ESRL GFSv2 have a peak weaker than observed. The multimodel ensemble mean peak precipitation is about $3 \mathrm{~mm}^{\text {day }}{ }^{-1}$ compared to the observed peak of about $3.5 \mathrm{~mm}^{\text {day }}{ }^{-1}$.

\section{Atmosphere-ocean conditions during the 2011-14 winters}

Figure 3 shows maps of the 2011/12,2012/13, and 2013/ 14 November-April winter half-year U.S. Climate Division precipitation, NCEP-NCAR reanalysis $200-\mathrm{mb}$ geopotential heights $(1 \mathrm{mb}=1 \mathrm{hPa})$, and SST anomalies, all relative to the common 1949-April 2014 period. California, and most of the western United States, had below normal precipitation anomalies for all three winters. Parts of the central and eastern United States were, in contrast, wet during these winters. There were some similarities in the SST conditions for the last three winters. The winter of 2011/12 had quite striking La Niña conditions, with SSTs colder than normal by up to $1 \mathrm{~K}$, along with the classic La Niña pattern of cold SSTs along the western coast of North America and warm 
(a) 2011-2012

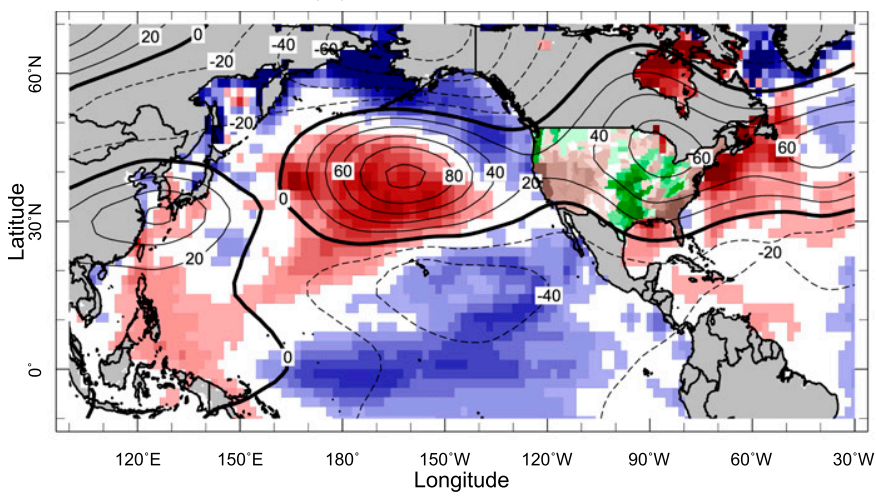

Nov 2011 - Apr 2012

(b) 2012-2013

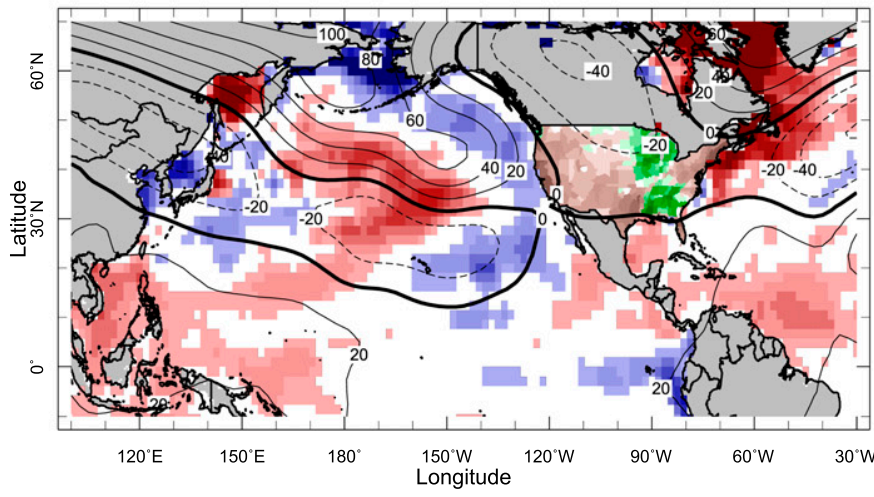

Nov 2012 - Apr 2013

(c) 2013-2014

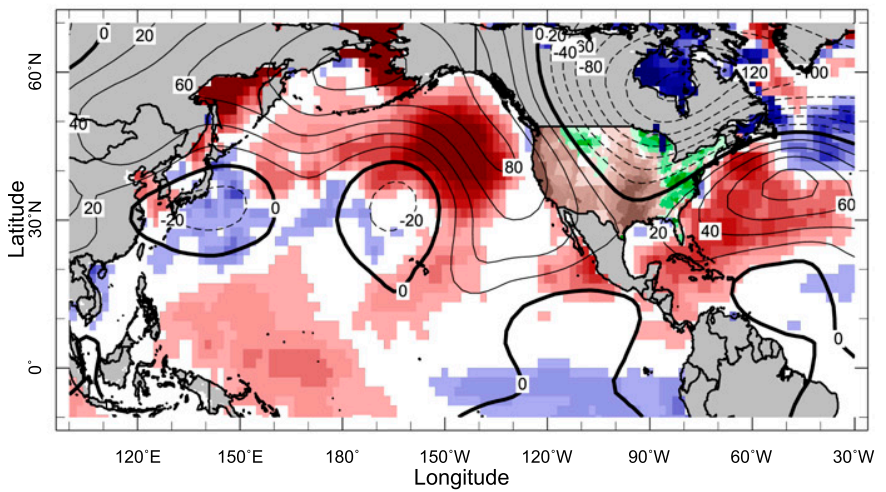

Nov 2013 - Apr 2014

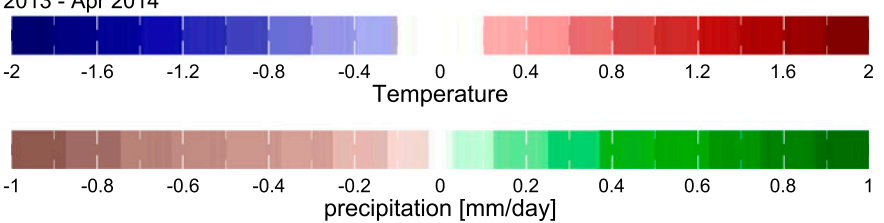

FIG. 3. The observed 200-mb height anomalies (contours, m), SST (colors, ocean, K), and U.S. precipitation (colors, land, $\mathrm{mm} \mathrm{day}^{-1}$ ) anomalies for winter (top) 2011/12, (middle) 2012/13, and (bottom) 2013/14. 
SSTs in the central North Pacific Ocean and far western tropical Pacific Ocean. The La Niña waned in winter 2012/13, leaving weak tropical SST anomalies and much weaker North Pacific SST anomalies as well. In winter 2013/14, the equatorial eastern Pacific cooled and the western tropical Pacific warmed while a strong warm anomaly developed in the central, and especially eastern, North Pacific Ocean. The state of ENSO during winters 2012/13 and 2013/14 was "ENSO neutral."

The geopotential height anomalies show the most obvious differences between the three winters. In 2011/12 there were low heights above the tropical Pacific, typical of La Niña conditions, and a rather zonally oriented ridge from the western North Pacific across North America to the midlatitude Atlantic Ocean, a pattern that is not exactly typical of La Niña winters. In 2012/13, tropical height anomalies were weaker, but there was a ridge over the North Pacific centered near the Aleutian Islands. The winter of 2013/14 was different again, with weak tropical height anomalies but with an extremely strong ridge stretching from the Bering Sea down the west coast of North America all the way to Central America and an intense trough centered over Hudson Bay.

The height anomalies were in general coherent in the vertical and can be used to largely explain the North Pacific SST anomalies in terms of surface flow and heat flux anomalies, consistent with analyses from Davis (1976) to Johnstone and Mantua (2014) that North Pacific SST anomalies are primarily driven by atmospheric circulation anomalies. For example, southerly flow around the North Pacific high is consistent with anomalous warming of the central North Pacific by warm, moist advection that reduces sensible and latent heat loss as well as reduced wind speed (and hence warming) on the southern flank of the anomalous high, with additional possible warming from anomalous Ekman drift. Similar arrangements of wind and SST anomalies are seen in the other two winters, for example, the localized very warm SST anomalies in the northeastern Pacific in winter 2013/14 under strong southerly wind anomalies that have been explained as an ocean response to atmospheric forcing by Bond et al. (2015).

These examinations of the observed conditions during the 3-yr drought suggest that it arose from a series of winter circulation anomalies, all of which involved high pressure over the North Pacific immediately upstream from California, and which can be expected to be associated with dry, subsiding air and a lack of moisturebearing low pressure systems, but with the conditions in each winter not exactly like the other two. It also suggests that the strong SST anomalies in the North Pacific Ocean were themselves forced by the atmospheric circulation anomalies and, hence, not a primary causal mechanism [consistent with the analysis of Hartmann (2015)].

\section{The multimodel mean SST-forced simulation of the last three winters}

Figure 4 shows the seven-model average of the ensemble means of the simulated precipitation and 200-mb geopotential height for the past three winters. The ensemble mean of each model attempts to isolate the boundaryforced response common to the ensemble members while the average across the models seeks to identify responses that are robust and not model dependent. Comparing Fig. 4 with the observed state in Fig. 3, it can be seen that the multimodel ensemble mean (MEM) produces a ridge off the west coast of North America, over the eastern North Pacific, in each of the three winters. In winter 2011/12 the MEM has a classic La Niña pattern (Seager et al. 2014a) with a clear connection to cold SSTs and low geopotential heights in the tropical Pacific. In the following two winters the MEM produces a northwest-to-southeast-oriented ridge akin to that observed but quite different (even in quadrature over the Pacific-North America region) to the La Niñaforced 2011/12 pattern. The MEM also has low heights over northern Canada in the past two winters, providing for northerly flow anomalies over western Canada. Like the observations, the MEM height pattern hints at a wave train originating from the tropical Pacific. Consistent with the height pattern including the ridge off the west coast, and consistent with the observations, the MEM has dry anomalies in all winters over southwestern North America. These results suggest an oceanforced component to the 2011-14 California drought. Notably, however, the multimodel mean height anomaly at the west coast is about half that observed but the California (and west coast) precipitation anomaly is less than half that observed.

\section{The ocean, atmosphere, and precipitation states associated with all-California dry and wet winters in observations and SST-forced models}

Having examined the observed and modeled state during 2011-14, we next take a longer-term perspective and examine the typical atmosphere-ocean state during all-California droughts and pluvials, first in the observational record and then in SST-forced climate models.

\section{a. The observational record}

To analyze the observed state during droughts and pluvials, we determined the driest and wettest $15 \%$ of winter half years for all of California in the 1949/50 to 
(a) 2011-2012

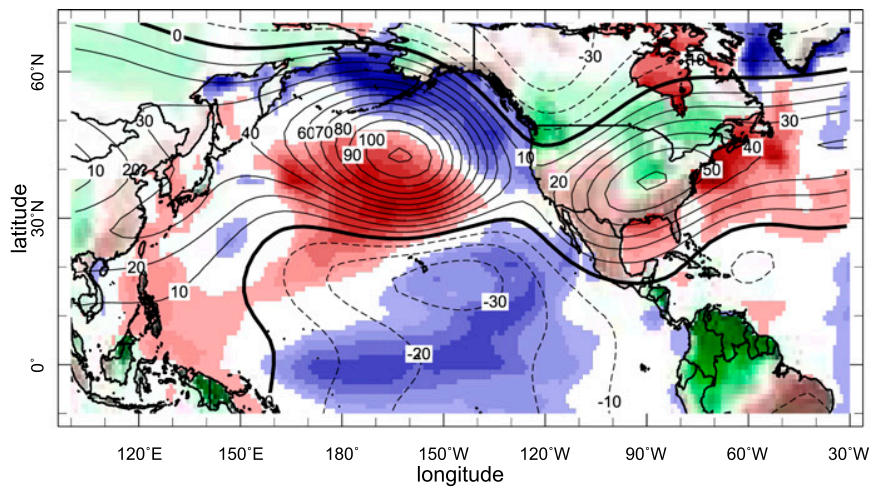

Nov 2011 - Apr 2012

(b) 2012-2013

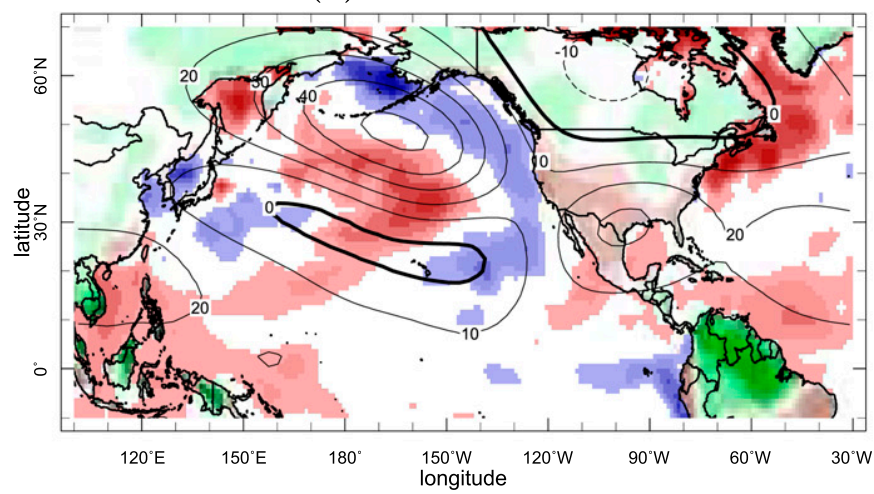

Nov 2012 - Apr 2013

(c) 2013-2014

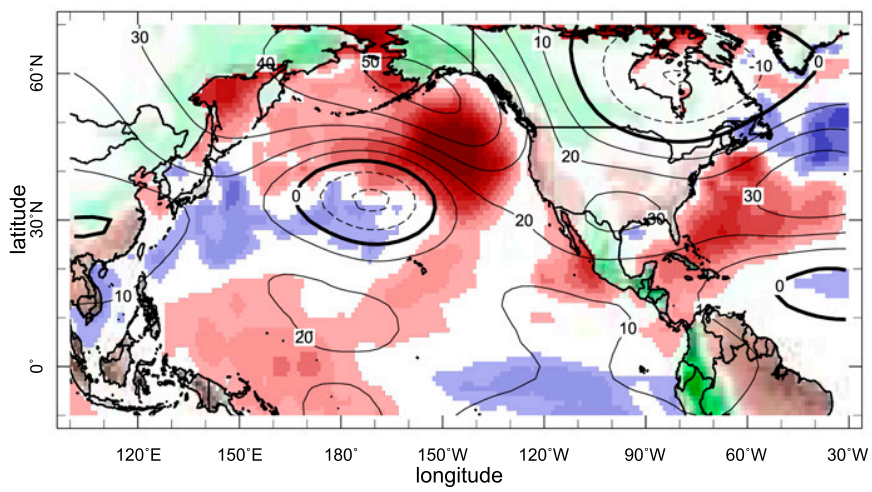

Nov 2013 - Apr 2014
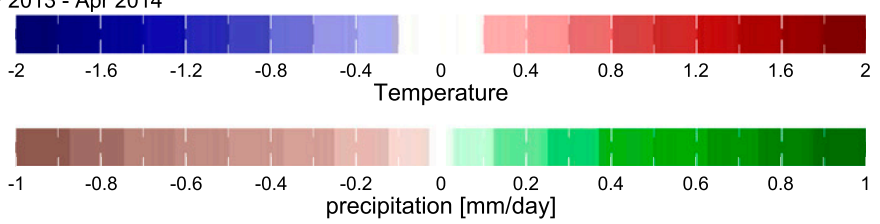

FIG. 4. The multimodel ensemble mean of seven SST-forced models' 200-mb height (contours, m), imposed SST (colors, ocean, K), and U.S. precipitation (colors, land, $\mathrm{mm} \mathrm{day}^{-1}$ ) anomalies for winter (top) 2011/12, (middle) 2012/13, and (bottom) 2013/14. 
2010/11 period. ${ }^{1}$ This excludes the 2011-14 drought winters so that they can be cleanly compared to the normal drought or pluvial state. We begin the analysis in 1949 to correspond to the beginning of the NCEPNCAR reanalysis data from which we use the geopotential height fields. Figure 5 shows in its top left panel the anomalies of U.S. precipitation, 200-mb heights, and SSTs for the $15 \%$ of driest California winter half years. The driest winters tend to be dry along the entire U.S. West Coast and associated with an anomalous high pressure system centered just west of Washington State, with an anomalous low just south of the Aleutian Islands. The SST anomalies in the North Pacific are consistent with atmosphere circulation forcing: cold in the western North Pacific under northwesterly and westerly flow that will induce cooling by cold, dry advection and increased wind speed and weak warm conditions under southerly flow over the eastern North Pacific. Notably, there are no appreciable SST or height anomalies in the tropics indicating that the typical California drought winters are not systematically forced from the tropics. The companion figure for the $15 \%$ of wettest California winters is shown in the top left panel of Fig. 6. For California wet years the entire western region of the United States tends to be wet, and there is a low pressure system centered west of Oregon. In this case, and unlike the case for dry winters, the low is clearly associated with a subtropical high to its south and a warm tropical Pacific Ocean, a classic El Niño-like arrangement of SST and height anomalies. These two results indicate an interesting and impressive nonlinearity in California climate variability: while wet winters are usually El Niño winters, dry winters are not usually La Niña winters. Instead, it appears that the typical dry winters are more related to a local North Pacific-North America wave train of presumed internal atmospheric origin.

\section{b. The model record}

For any model the individual ensemble members are begun with different initial conditions and have different sequences of random internal atmospheric variability together with an SST-forced component common to all. To examine the atmosphere-ocean states for modeled California dry and wet winters, and to allow for the possibility that these are generated by atmospheric processes alone, we identified the driest and wettest $15 \%$ of winters in each ensemble member and then averaged the results across the

\footnotetext{
${ }^{1}$ The wettest winters were 1951/52, 1957/58, 1968/69, 1977/78, $1980 / 81,1982 / 83,1994 / 95,1997 / 98$, and 2005/06 and the driest winters were 1956/57, 1958/59, 1963/64, 1975/76, 1976/77, 1986/87, 1989/90, 1993/94, and 2006/07.
}

ensemble to derive the dry and wet patterns for each model. The entire lengths of the ensembles, but excluding the 2011-14 winters, were used and anomalies are relative to each model's long-term climatology.

Results are shown in Figs. 5 and 6 for dry and wet composites, respectively. All models correctly have a high pressure anomaly west of Washington state during California dry winters. The CCM3, NCEP GFSv2, and GEOS-5 models correctly have this high appearing as a midlatitude wave while the other models have a wave train connected to the tropics and a La Niña-like SST anomaly. The midlatitude SST anomalies seen in observations to accompany the circulation anomaly are not seen in the model runs. This is partly because the SSTs are not coupled in the models and cannot respond to the atmospheric circulation anomalies as happens in nature and because extratropical SSTs are generally ineffective in forcing drought-producing conditions.

For the California wet years, all of the models have an anomalous low pressure system off the west coast connected with tropical height and SST anomalies that are a clear expression of El Niño. This much is observed. While all the models are roughly correct in this sense, the results suggest that only CCM3 and GEOS-5 correctly represent the nonlinearity of the California precipitation relationship to SST anomalies while ECHAM4.5, in particular, is too linear.

The asymmetry regarding tropical forcing arises from two plausible physical factors. One is the different height teleconnections for La Niña and El Niño events. Tropical Pacific SST anomalies for La Niña events tend to be to the west of those for El Niño events, with the latter forcing a wave pattern with strong westerly anomalies at the west coast at the latitude of California while, for La Niña events, the wave train is phase-shifted westward and there are weaker northwesterly anomalies over the Pacific Northwest (Haston and Michaelsen 1994; Hoerling et al. 1997, 2001; Lin and Derome 2004; Wu and Hsieh 2004; Peng and Kumar 2005; Kumar et al. 2005; Schubert et al. 2008; Zhang et al. 2014). A second is the skewness in tropical Pacific SST forcing itself, with a few very strong El Niño events that have no La Niña counterpart. These strong El Niño events (e.g., 1982/83 and 1997/98) generate a statewide California wet signal that dominates the El Niño composite (Hoerling and Kumar 2002).

\section{Model simulation of the 2011/12 to 2013/14 winters}

\section{a. The ensemble mean response}

Figures 7, 8, and 9 show the model-by-model ensemble mean precipitation and 200-mb height anomalies simulated by the SST-forced models presented along 
Observed

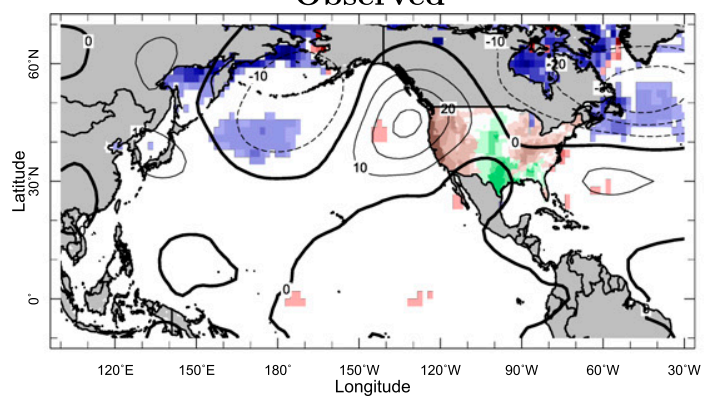

CAM 4

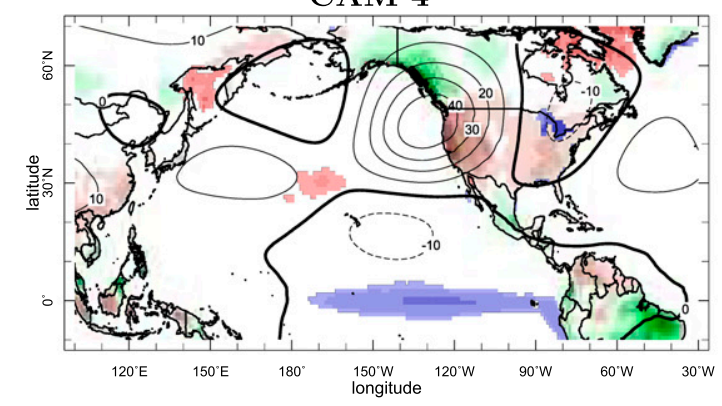

ECHAM 5

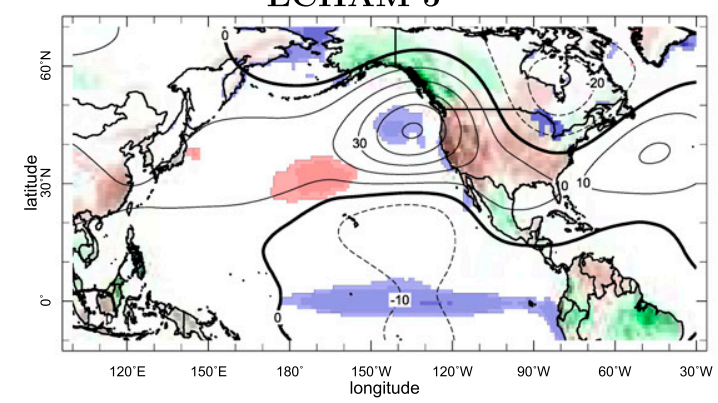

ESRL CFSv2

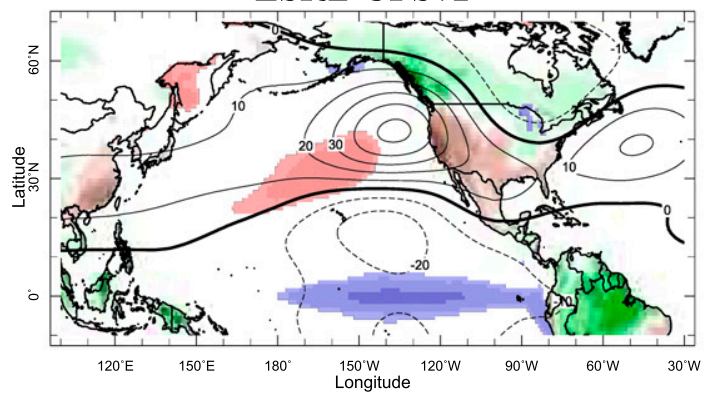

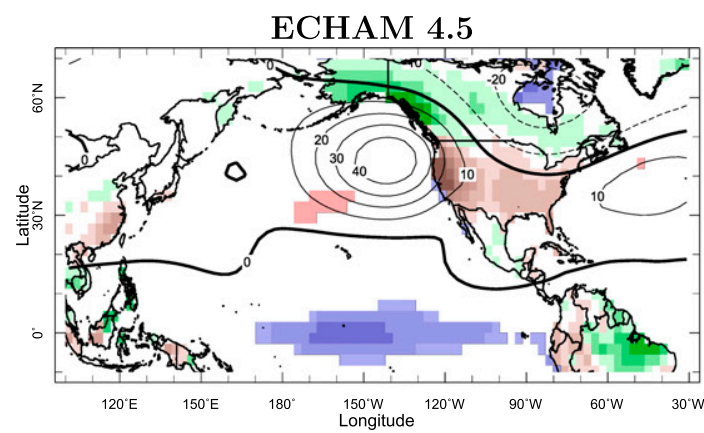
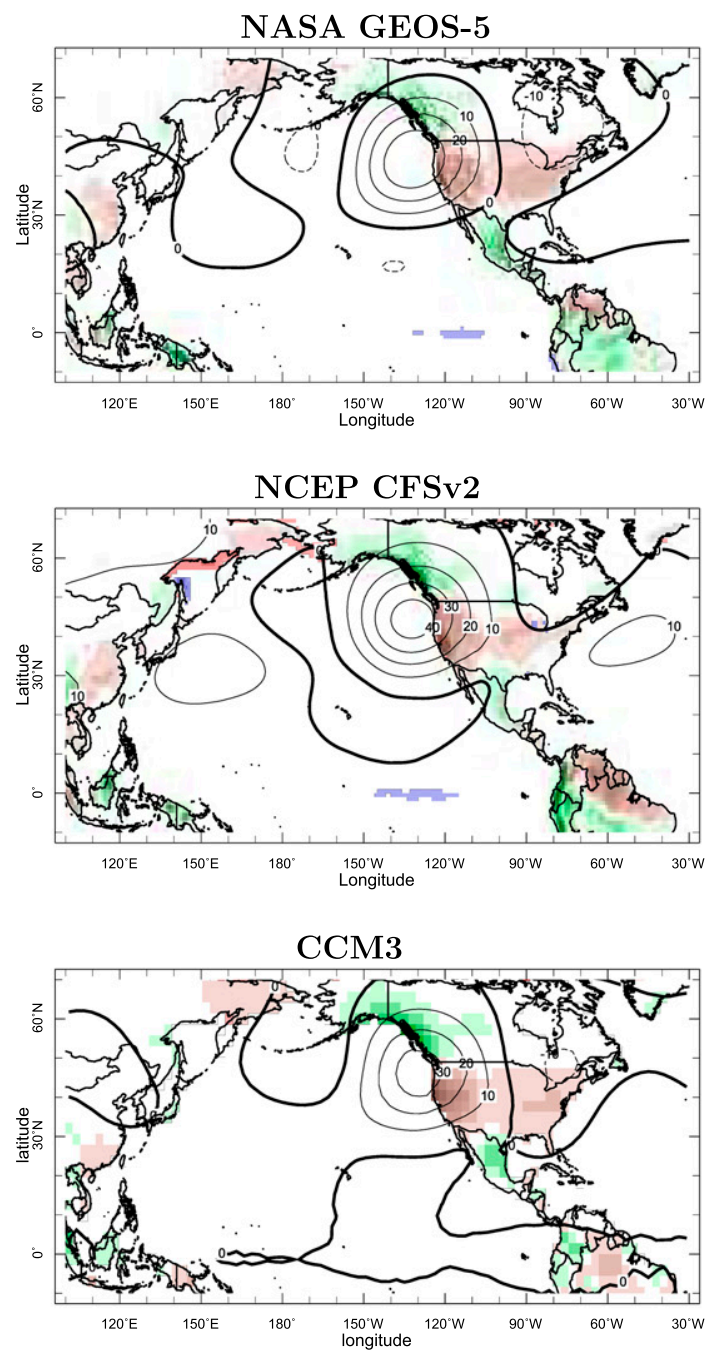
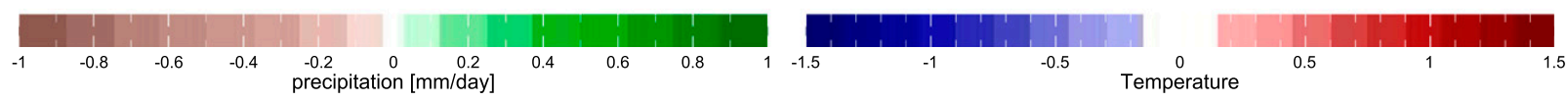

FIG. 5. The 200-mb height (contours, m), SST (colors, ocean, K), and precipitation (colors, land, $\mathrm{mm} \mathrm{day}^{-1}$ ) anomalies composited over the driest $15 \%$ of California winters for (top left) observations (only U.S. precipitation shown) and for the SST-forced models (remaining panels). For the models the $15 \%$ driest winters were identified in each ensemble member and the composites were then formed by averaging across the ensemble. SST anomalies are not plotted for absolute values less than $0.15 \mathrm{~K}$. 

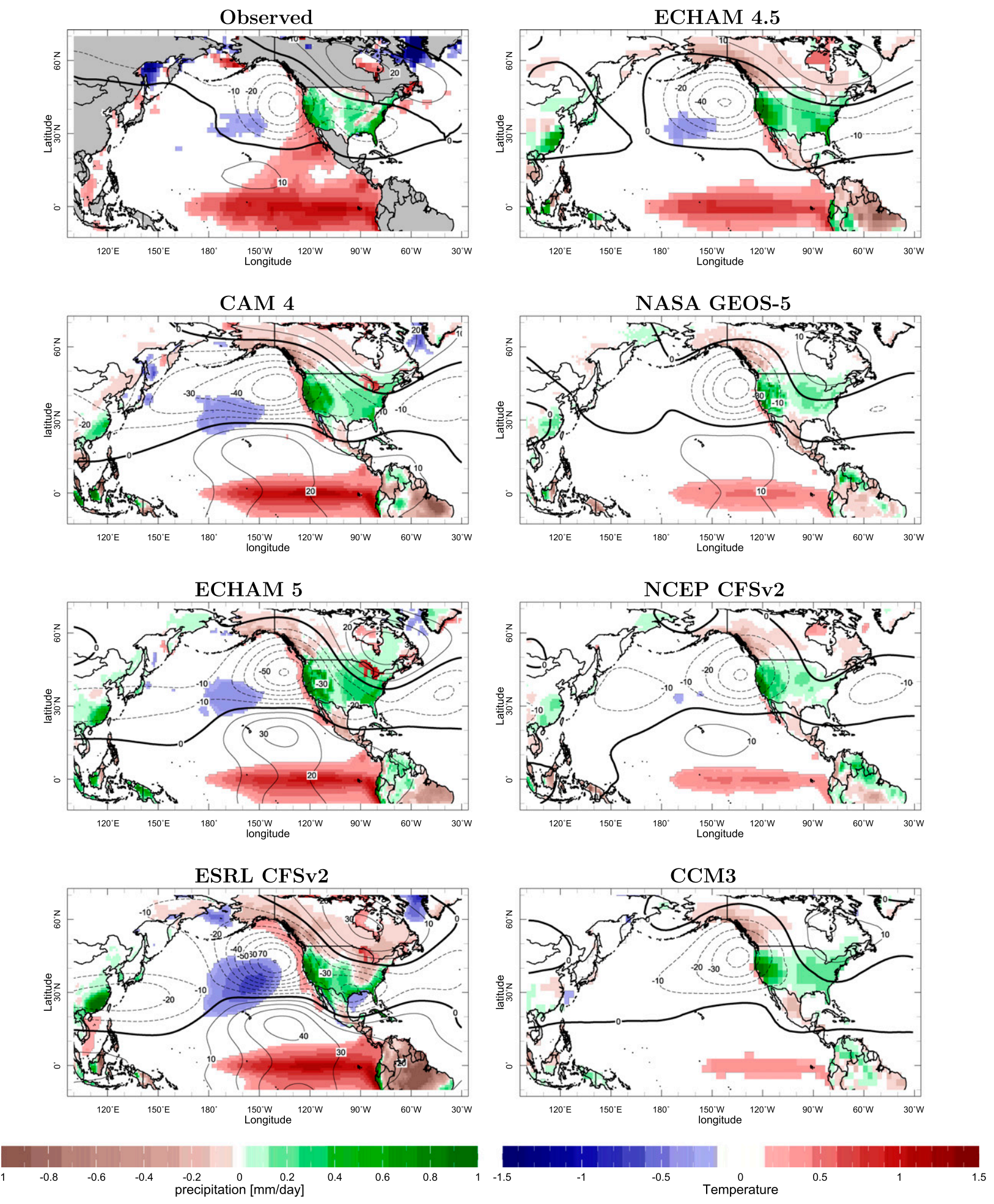

FIG. 6. As in Fig. 4, but for composites of California wet winters. 
Observed

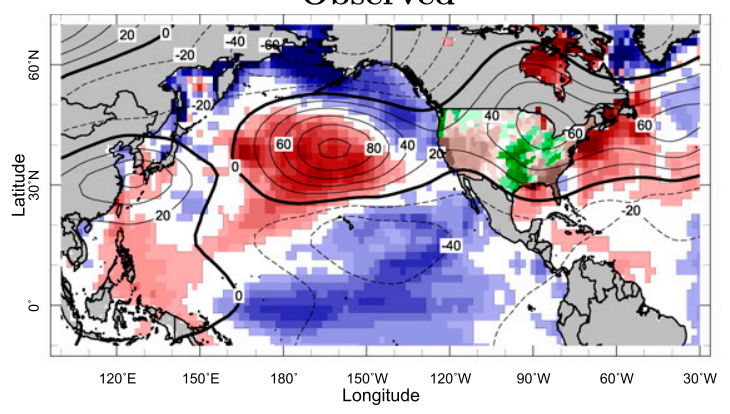

Nov 2011 - Apr 2012

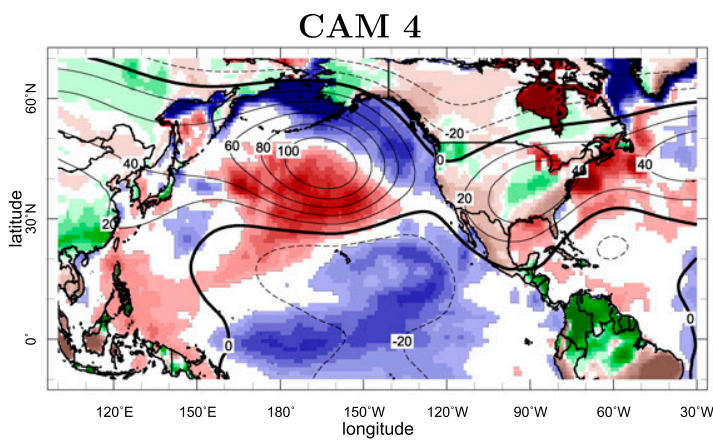

Nov 2011 - Apr 2012

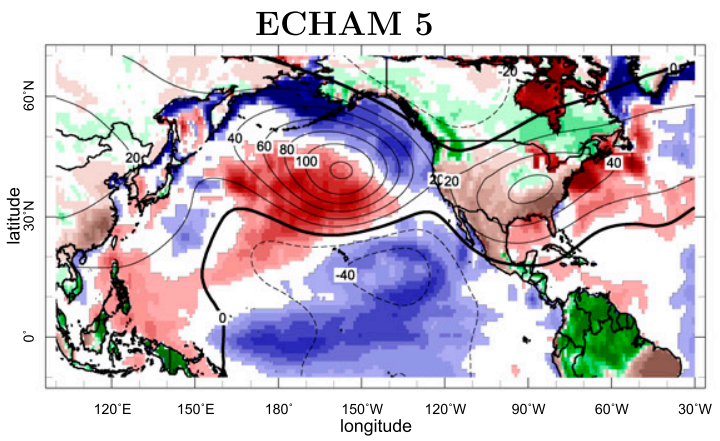

Nov 2011 - Apr 2012

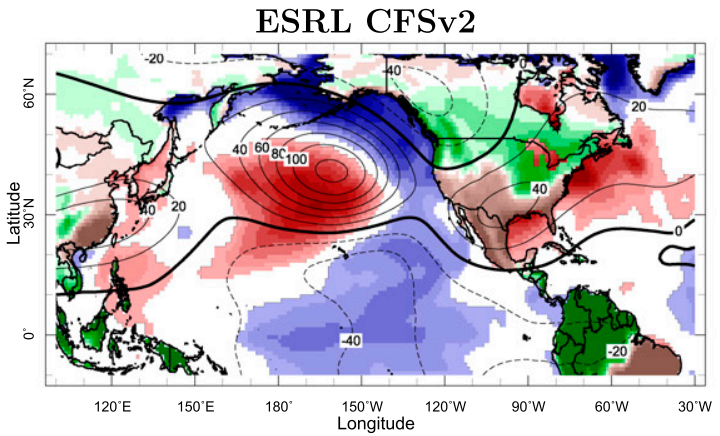

Nov 2011 - Apr 2012

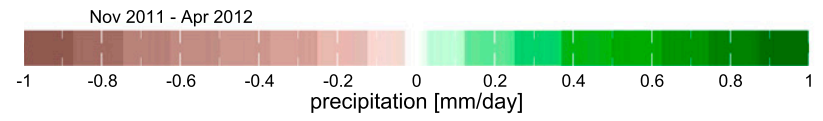

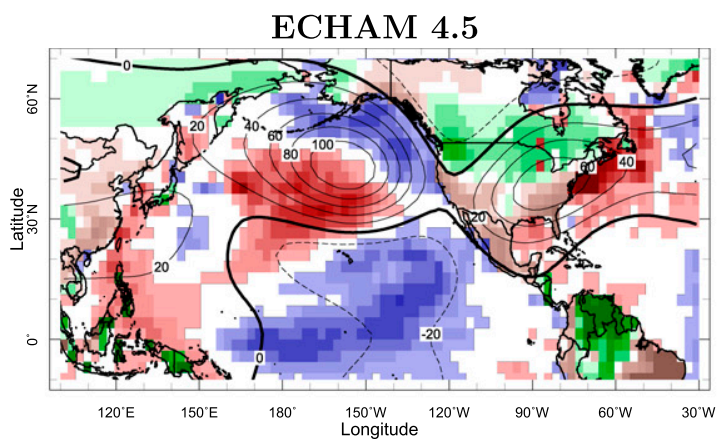

Nov 2011 - Apr 2012

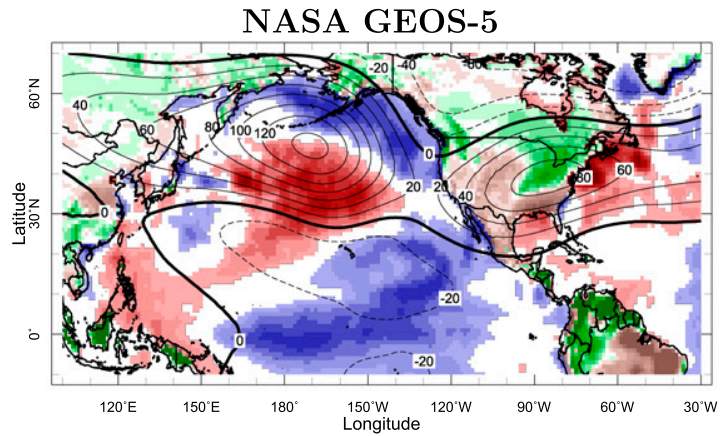

Nov 2011 - Apr 2012

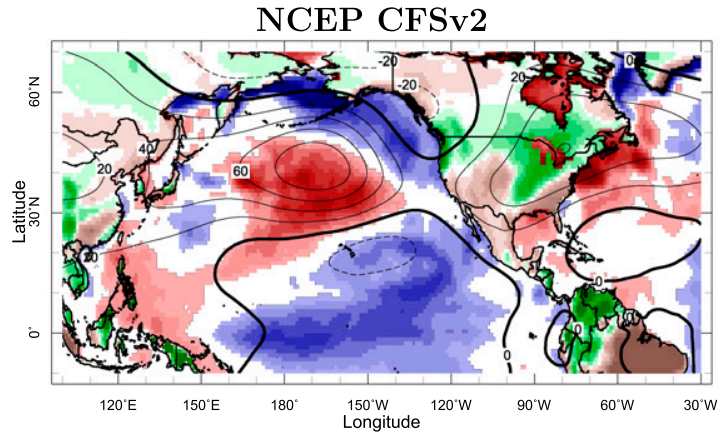

Nov 2011 - Apr 2012

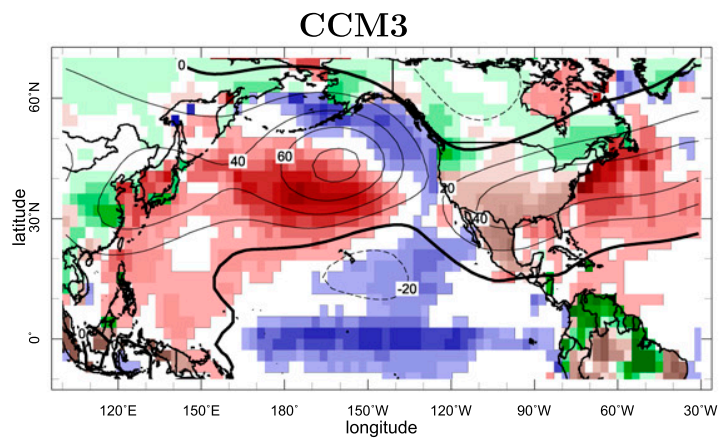

Nov 2011 - Apr 2012

FIG. 7. The 200-mb height (contours, m), SST (colors, ocean, K), and precipitation (colors, land, mm day ${ }^{-1}$ ) anomalies for (top left) observations (precipitation plotted for the U.S. only) and (remaining panels) the ensemble means of model simulations for the winter of November 2011 to April 2012. 
Observed

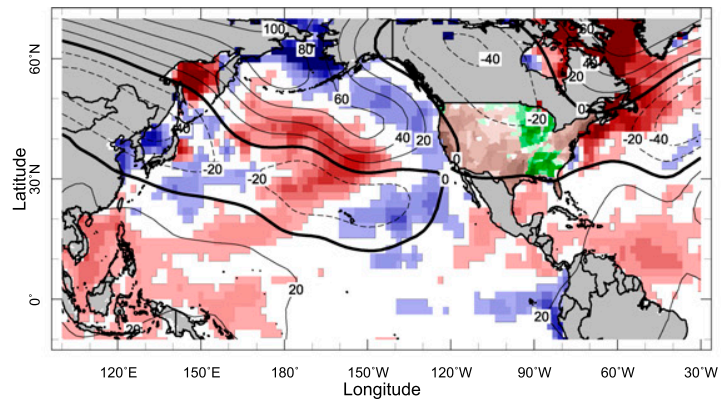

Nov 2012 - Apr 2013

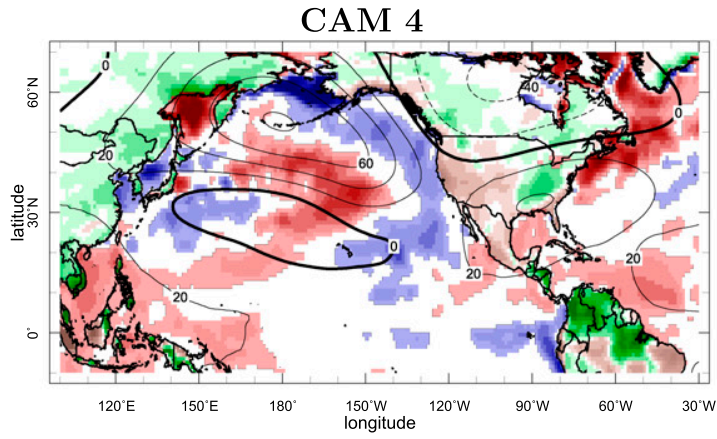

Nov 2012 - Apr 2013

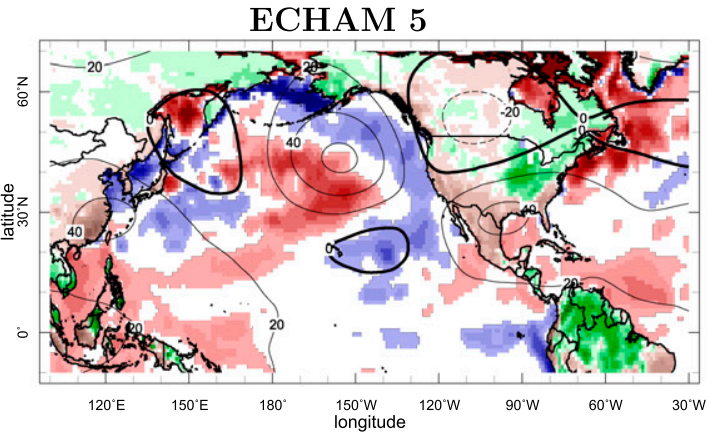

Nov 2012 - Apr 2013

ESRL CFSv2

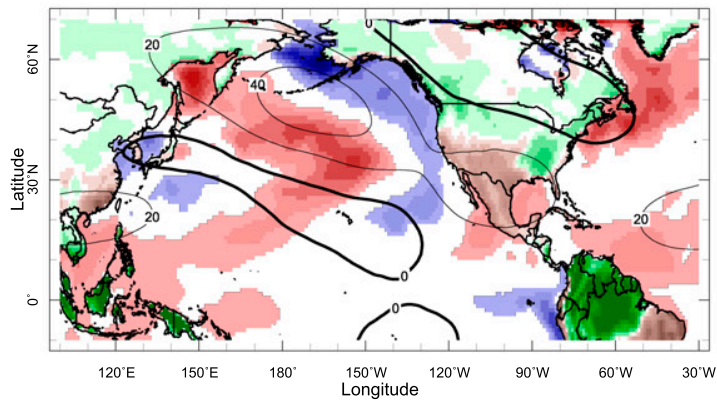

Nov 2012 - Apr 2013

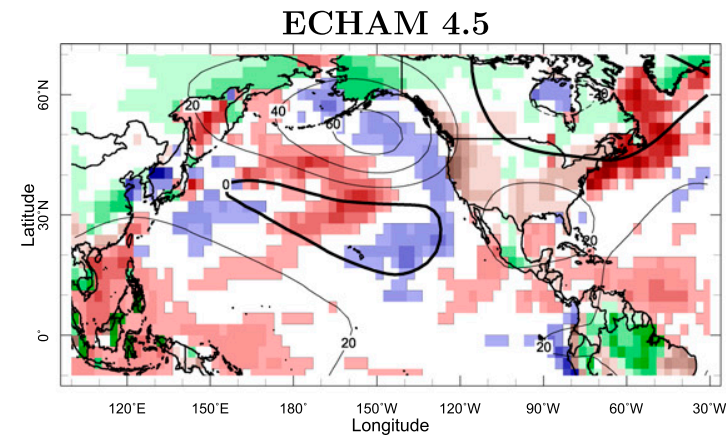

Nov 2012 - Apr 2013

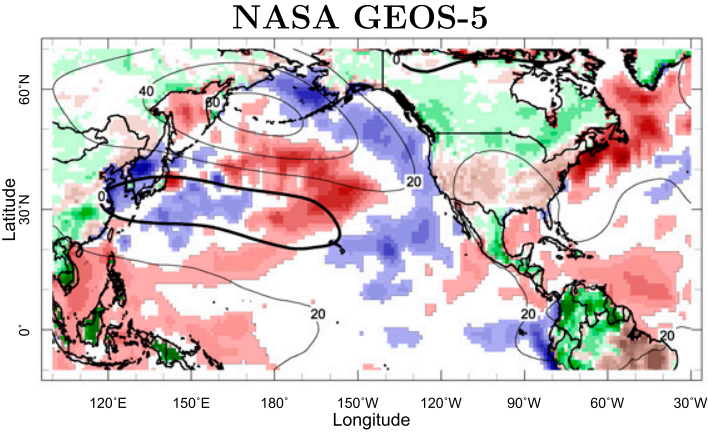

Nov 2012 - Apr 2013

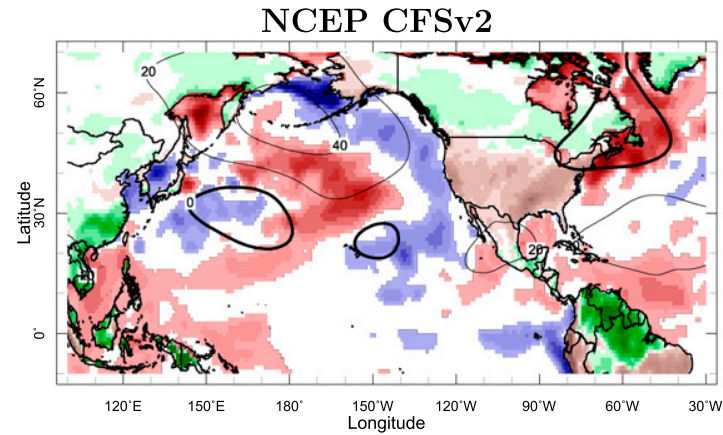

Nov 2012 - Apr 2013

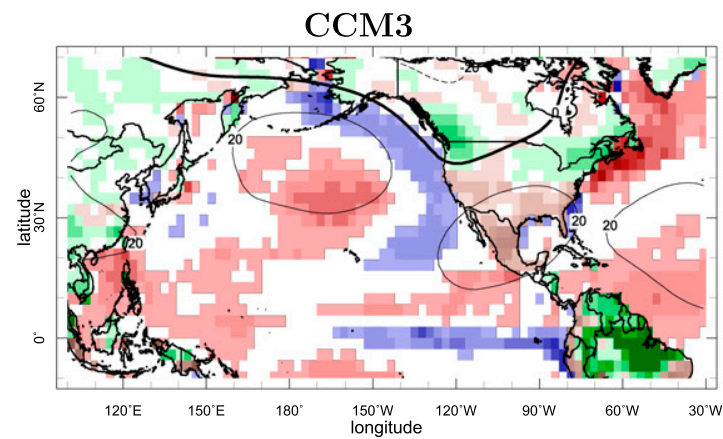

Nov 2012 - Apr 2013
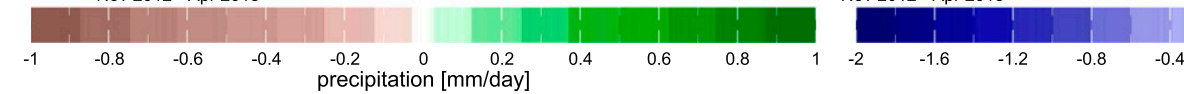

FIG. 8. As in Fig. 6, but for the winter of November 2012-April 2013. 
Observed

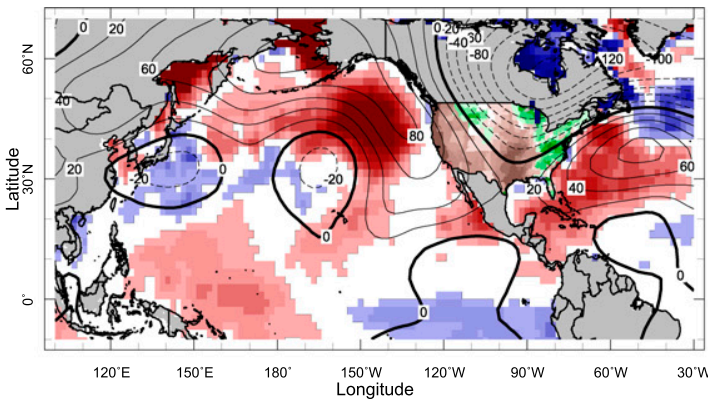

Nov 2013 - Apr 2014

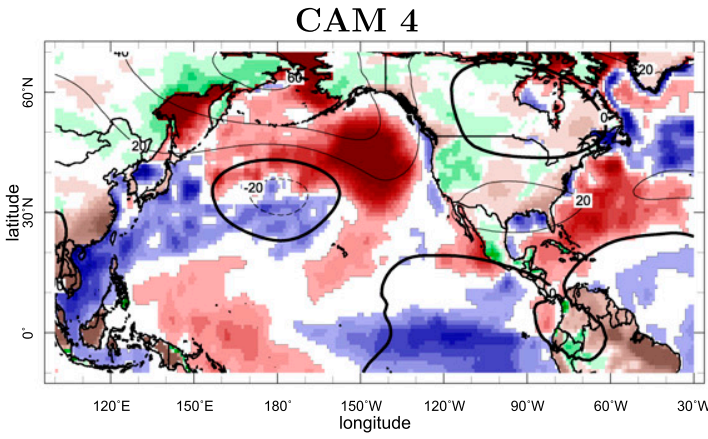

Nov 2013 - Apr 2014

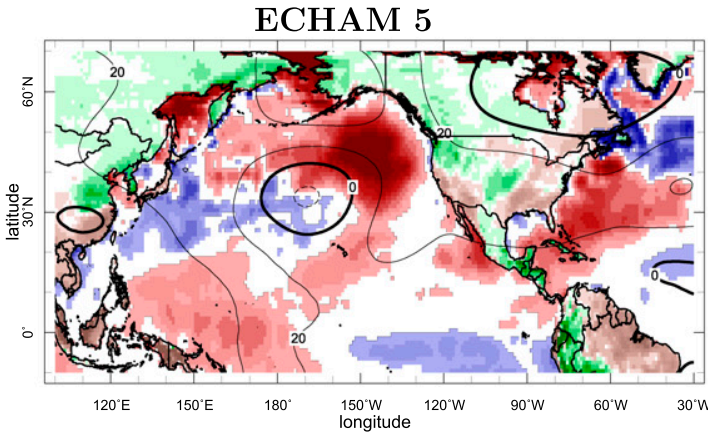

Nov 2013 - Apr 2014

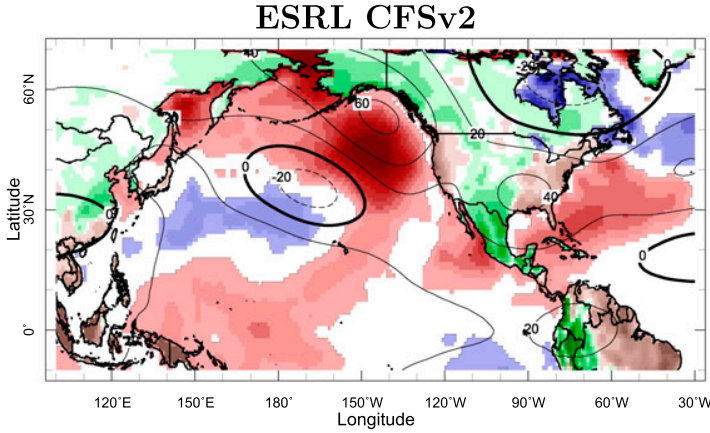

Nov 2013 - Apr 2014

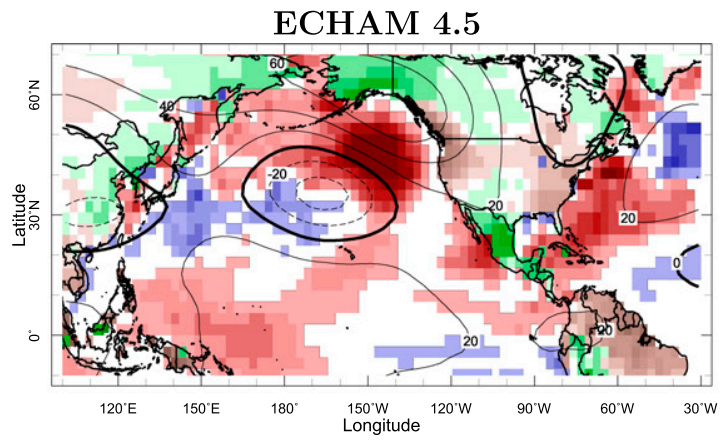

Nov 2013 - Apr 2014

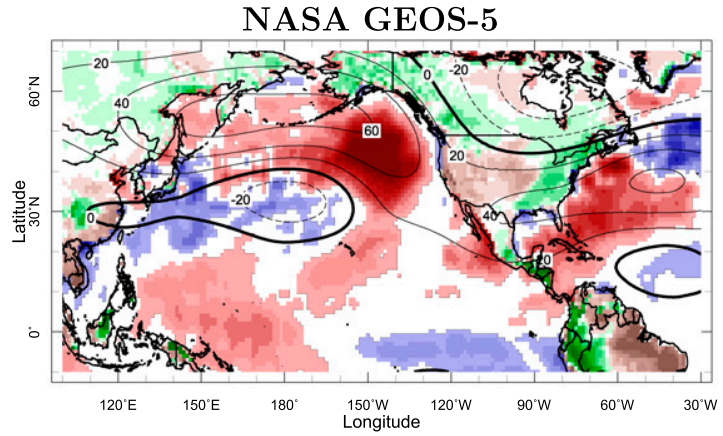

Nov 2013 - Apr 2014

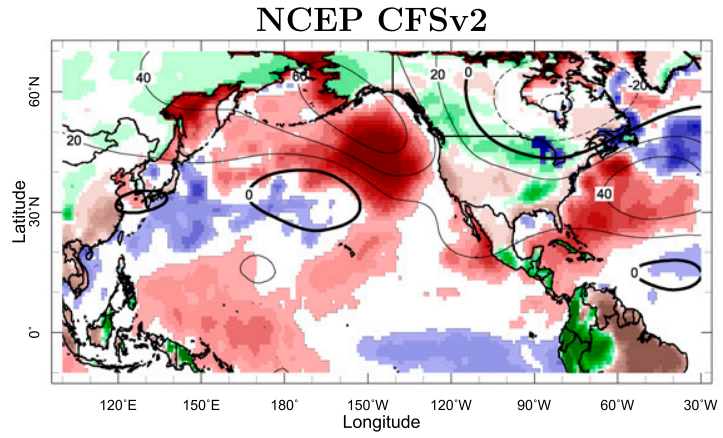

Nov 2013 - Apr 2014

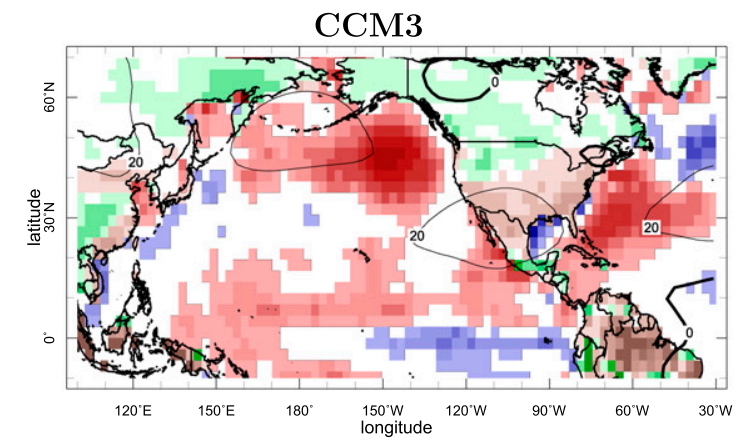

Nov 2013 - Apr 2014 
with the observations (repeated from Fig. 3). SST anomalies are also shown since the different models used different SST datasets, and hence, this provides an idea of uncertainty in the SST. The ensemble means approximate the SST-forced and thus potentially predictable component.

The pattern of forced signals in most individual models captures the essential observed Pacific-North America height and U.S. West Coast precipitation anomalies observed during the 2011-14 winters. However, none have height and precipitation anomaly amplitudes as large as those observed. This suggests that an SST-forced component to these anomalies is not a full explanation, leaving a potential and important role for a coincident and constructive influence of internal atmosphere variability. During winter 2011/12 (Fig. 7), there were extensive cold SST anomalies in the central and eastern equatorial Pacific Ocean characteristic of a La Niña event. The models respond realistically in a manner consistent with known La Niña teleconnections (e.g., Hoerling et al. 1997; Seager et al. 2014a) with low height anomalies in the tropics, a high anomaly over the North Pacific Ocean extending across southern North America into the Atlantic Ocean, and a low over western Canada. The observed height anomalies had some similarity to this but were more zonally oriented across the Pacific-North America-Atlantic sector. The model signal of California and the U.S. West Coast as drier than normal is consistent with observations (Seager et al. 2014a).

In the following two winters, 2012/13 and 2013/14 (Figs. 8, 9), the eastern equatorial Pacific SST anomalies had weakened to near normal. Despite this, most of the models still placed a high pressure anomaly over the west coast, especially in winter 2013/14. In this case the high, over the North Pacific Ocean, is far to the north of the typical La Niña-forced high. Given that the ridge is associated with a low height anomaly over the subtropical western Pacific, there is some hint that these may be a wave pattern forced from the tropical to subtropical IndoPacific region. During these two winters most of the models also produce drier-than-normal conditions across the U.S. West Coast, including California. The height and precipitation anomalies are, however, much weaker than those that actually occurred. Nonetheless, of the 21 simulated ensemble mean winters ( 3 years times 7 models), 20 were drier than normal in California. By this elementary test, there is widespread model consensus that the SST conditions of the last 3 years should have heavily tilted California toward drought.

CCM3 is probably the most unrealistic model in simulating the west coast ridge of winter 2013/14. It is also the only one to use the Hadley Centre SST data.
We reran a 16-member ensemble with CCM3 from January 2013 to April 2014 using the NOAA ERSST dataset and found that the model did reproduce the west coast ridge with a fidelity comparable to that of the other models. The Hadley Centre SST anomalies for the past winter differ to those in the Hurrell et al. (2008) and NOAA datasets primarily by being weaker. The success of the models forced with the latter datasets suggests that their SSTs are probably more correct than those in the Hadley Centre data, but this source of uncertainty needs to be noted, tracked down, and assessed.

\section{b. The ensemble spread of precipitation anomalies for the past three winters}

The spread among individual realizations within model ensembles provides a model-based assessment of the boundary-forced signal to internal atmospheric noise ratio, thereby indicating the likelihood for detecting (and potentially predicting) the forced drought signal. In Fig. 10 we show this information in the form of box-and-whisker plots for all-California precipitation for each of the three winters and the three-winter average and for each model. The 25 th and 75 th percentiles of the ensembles are shown as the limiting horizontal lines of the boxes with the mean as the line crossing the boxes while the median is the star and the range is given by the limits of the whiskers. The observed values are shown by crosses. For 2011/12 the mean and median precipitation anomalies for all models were drier than normal, and the observed anomaly was at or above the 25th percentile for the ESRL GFSv2 and the ECHAM models. For winter 2012/13 all the means and medians and a clear majority of the multimodel ensemble indicated drier-than-normal conditions, and the observed anomaly fell within the allmodel range. For winter 2013/14 all model ensembles except CAM4 had means and medians drier than normal but with the observed value falling at the edge of, or beyond, the model distribution. However, the observed anomaly, at about $-1.4 \mathrm{~mm} \mathrm{day}^{-1}$, does not appear to be beyond the full range of possibilities of the models, based on looking at the model extremes for all three winters. For the three-winter average the observed anomalies are also at the range of, or beyond the range of, simulations, but not so far beyond as to appear beyond the capability of the models to generate such intense 3-yr droughts. (Examining the full range considering all winters in all ensemble members confirms that the models are capable of getting absolute and percentage declines in precipitation of the magnitude seen in the last three winters and the three-winter average.) Notably, the model with the largest ensemble (ESRL GFSv2, 


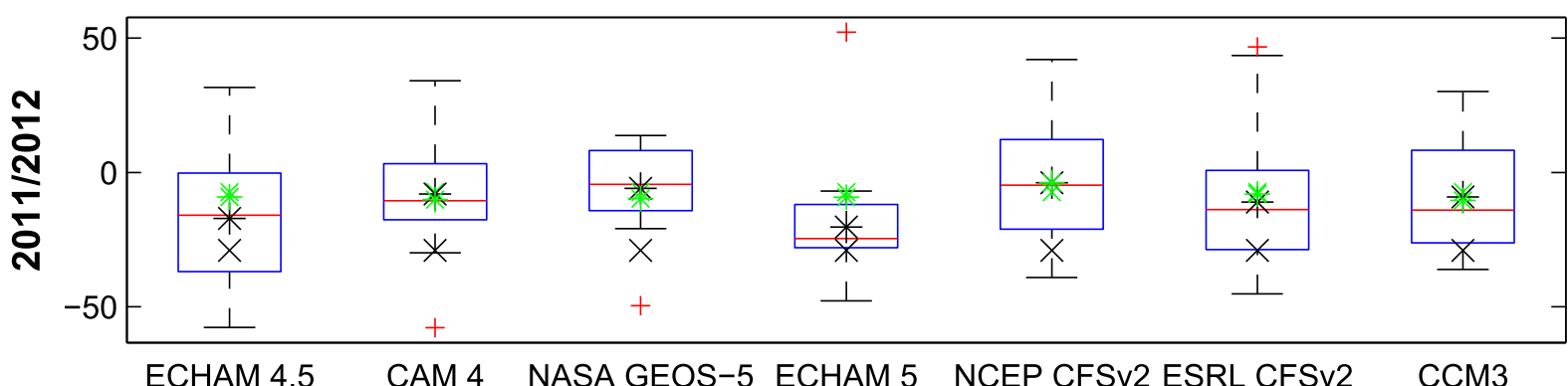

ECHAM 4.5 CAM $4 \quad$ NASA GEOS-5 ECHAM 5 NCEP CFSv2 ESRL CFSv2 CCM3
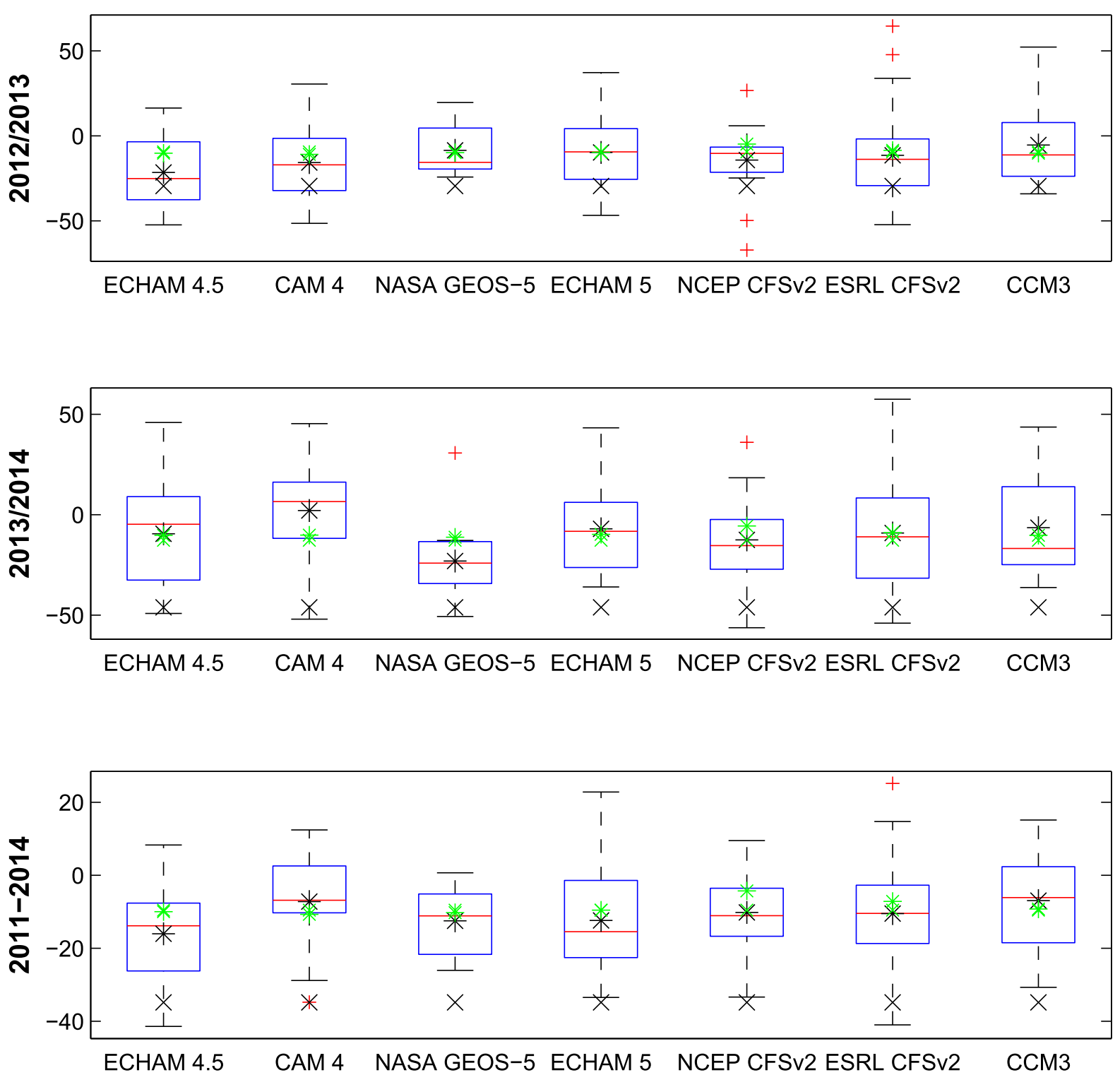

FIG. 10. Box-and-whiskers plots showing the mean (asterisk), median (horizontal red line inside boxes), 25th and 75th percentile spread (horizontal edges of boxes), and spread (whiskers) of the model ensemble, with outliers shown as red crosses, for each model and each of the past three winters. (bottom) The three-winter average. Also shown are the observed (green crosses) and modeled (green asterisks) 1979-2014 trends also expressed as percent of the 1979-2014 climatological mean. 
50 members) is the one that encompasses the extreme of winter 2013/14 and the 3-yr average, so it is possible the other models would have done also had their ensembles been larger. ${ }^{2}$

\section{On the role of SST anomalies in causing the 2011-14 California drought}

The results so far have suggested that, while California dry winters in general might arise from internal atmospheric variability, the 2011-14 winters likely contained a component of ocean forcing. The winter of 2011/12 was characterized by a moderately strong La Niña event, and its resulting teleconnection contributed to dry California conditions consistent with a modest La Niña-California dry relationship. The winters of 2012/13 and 2013/14 were, however, ENSO neutral and had different SST forcing.

To examine the nature of the forced signals during these two winters in more detail, we turn to the ensemble means of the model simulations that closely isolates the boundary-forced component. While many of the models used did also impose the observed time history of sea ice, it is considered that it is the SST that matters most (as will be seen). The ensemble sizes used here range from 12 members (GEOS-5) to 50 (ESRL GFSv2) members and are large enough to filter out much of the weather noise within each model.

Therefore, we computed the empirical orthogonal functions (EOFs) of the ensemble mean Northern Hemisphere 200-mb height field for winter half years in each model. This was done for the winters of 1979/80 2013/14 to match the time period that is covered by all the model simulations. The principal component (PC) associated with each EOF was then correlated with global winter SST anomalies to determine the pattern of SST anomalies that forced the circulation anomaly described by the EOF mode. In all models the first EOF is the El Niño-Southern Oscillation (ENSO) mode. This

\footnotetext{
${ }^{2}$ It is usually the case in climate research that the amplitudes of the climate anomalies being investigated are at the very limits of the range of model simulations. That this is usually so might be interpreted as indicating that the models have variability that is too weak. However, we prefer an interpretation in terms of a climate version of the weak anthropic principle (WAP). In cosmology, the WAP says that it is not surprising that the chance of the universe evolving to support sentient life is extremely small. That is because it is only in such a universe that we exist to ponder this question, while the much larger number of universes that could not support life would go unobserved. Similarly, in climate research we choose to only examine the interesting extreme events, while ignoring the vastly greater number of run-of-the-mill events, and hence are always looking at the most unusual climate anomalies. Our models confirm for us that these are indeed truly rare.
}

typically explains more than half of the Northern Hemisphere SST-forced variance of 200-mb heights and is clearly, and not surprisingly, the dominant mode of variability. The second EOF in all the models appears to be the decadal ENSO, or Pacific decadal variability mode. Like the first mode (although orthogonal to it), it has strong height expression in the tropics and a wave train extending across the Pacific and North America. The second-mode PC correlates to a meridionally broad SST anomaly centered on the central and eastern equatorial Pacific Ocean with opposite signed anomalies in most of the remainder of the World Ocean. Given the 1979-2014 time frame of analysis, and decadal shifts in 1976/77 and 1997/98, the PC also appears as a trend.

As shown in Fig. 11, in every model other than CCM3, the third EOF mode was a wave train that arched from the tropical western Pacific northeastward across the Pacific Ocean to North America and (in the phase shown) had a ridge extending from the northwest over the Bering Sea to the southeast over California at or just west of the North American coast. ${ }^{3}$ Also shown are the PCs that make clear that this is a mode of variability without any obvious trend to a preferred state. In many models the PC value for winter 2013/14 is strong and often the strongest in the record consistent with the dominance of this pattern in nature this past winter.

Finally, the PCs were regressed with global SST to determine what ocean climate variability was responsible for forcing this mode, and the resulting maps are also shown in Fig. 11, with regression coefficients only shown where significant at the $95 \%$ level. All the models agree that the west coast ridge pattern of height variability is forced by an intensified east-west SST gradient across the equatorial Pacific Ocean with both cool in the east and warm in the west consistent with the appearance of a wave train that includes the west coast ridge originating from the tropical Pacific. The SST correlations also show anomalies in the North Pacific, with warm anomalies extending northeast from the tropical western Pacific and also appearing in the central North Pacific. As for the observations in 2013/14, the warm anomaly in the central North Pacific can be understood in terms of the atmosphere driving the SST anomalies within southeasterly flow anomalies to the west of the west coast ridge.

In Fig. 12 we show the regression of the ensemble mean precipitation to the PC of the third mode (fourth

\footnotetext{
${ }^{3} \mathrm{CCM} 3$ seemed to mix this mode between the third and fourth EOFs, but after varimax rotating the first four EOFs, it appears as the fourth mode and that is what is shown in Fig. 11.
} 

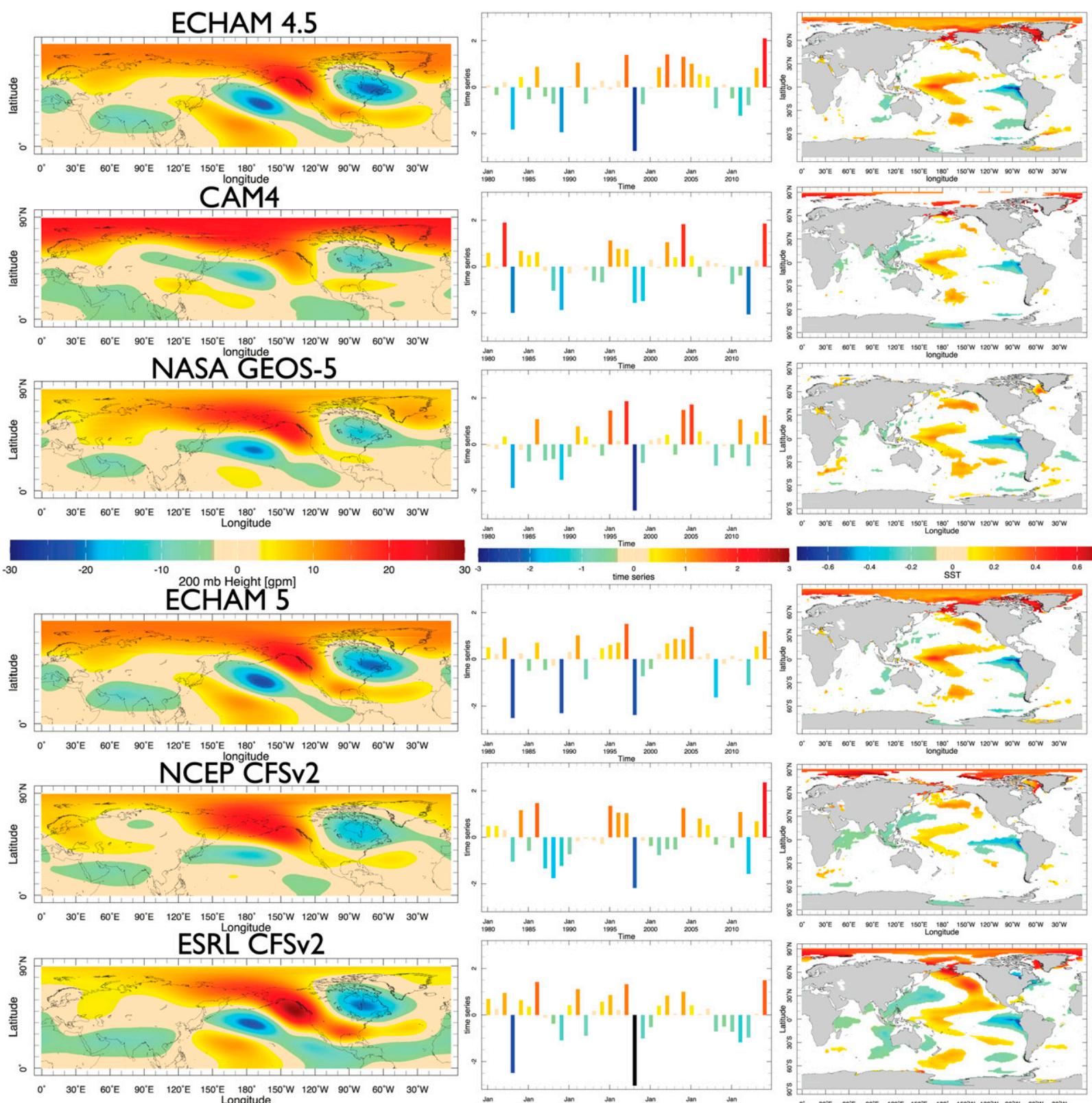

\section{CCM3}
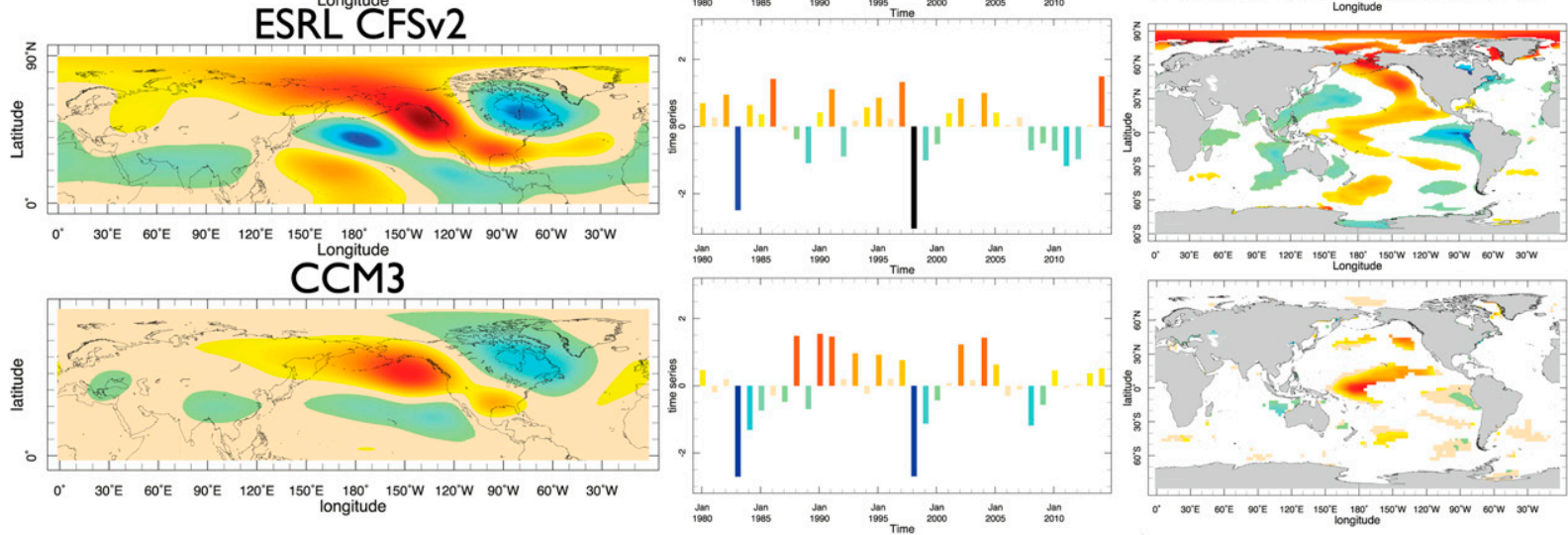

FIG. 11. (left) The 200-mb height (h) anomaly pattern associated with the third EOF mode (but fourth rotated mode for CCM3) of model ensemble mean Northern Hemisphere winter half-year 200-mb height for the 1979-2014 period. (center) The associated PC. (right) The regression of SST (K) on the third PC with values only shown where significant at the $95 \%$ level. 
ECHAM 4.5

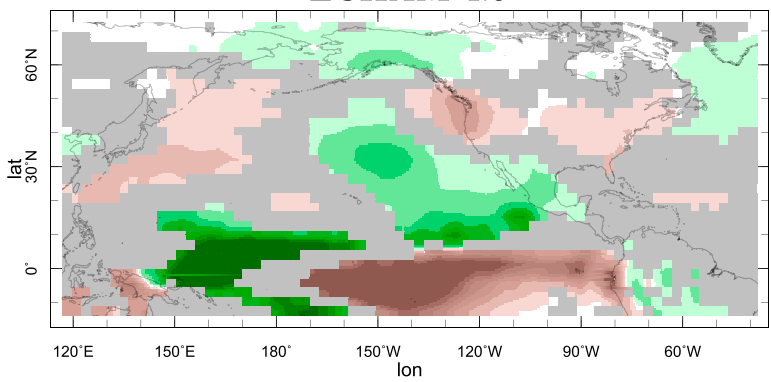

NASA GEOS-5

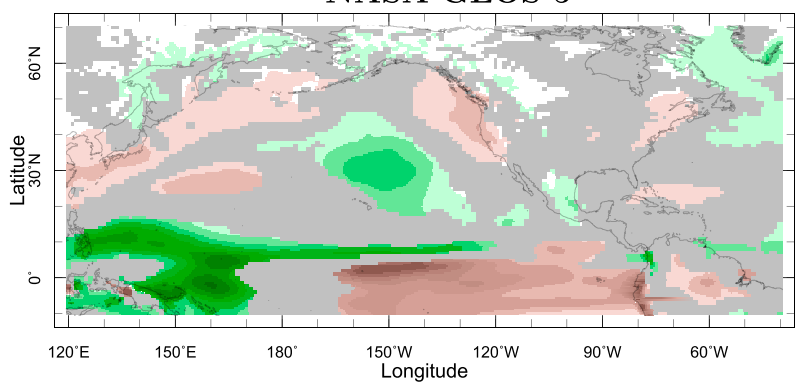

NCEP CFSv2

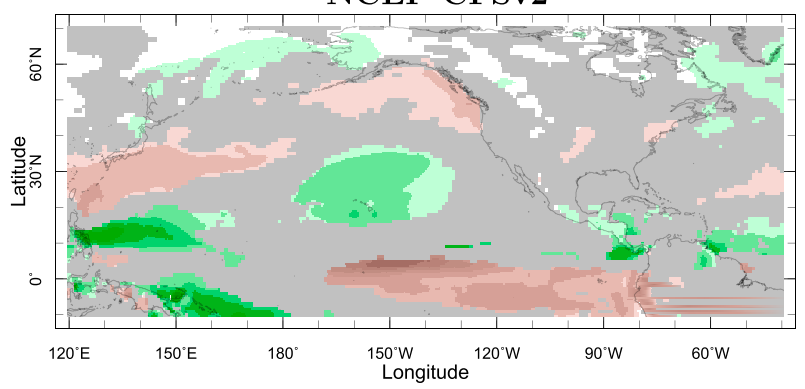

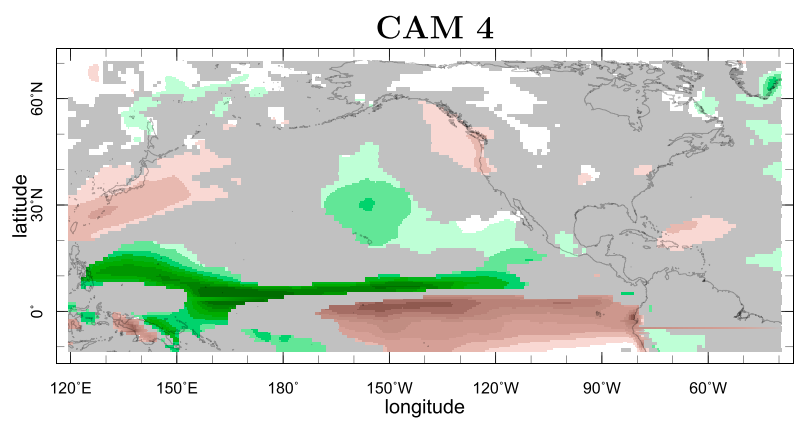

ECHAM 5

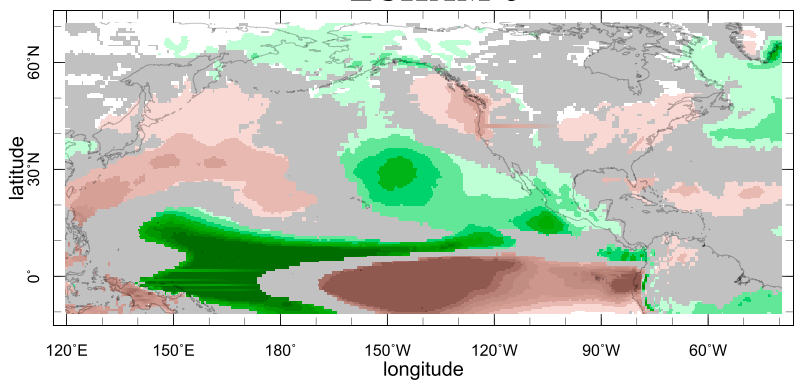

ESRL CFSv2

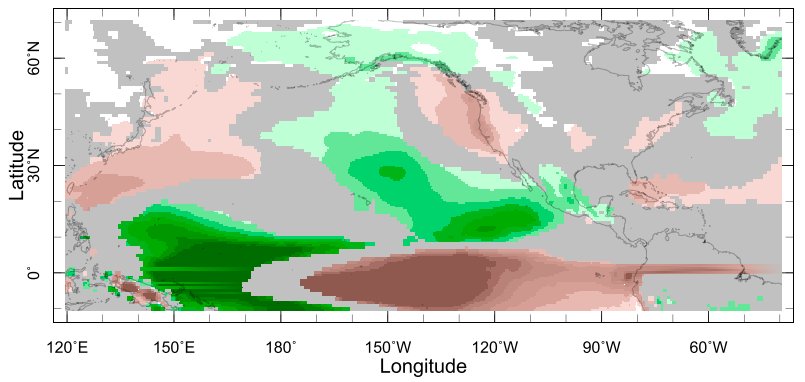

\section{CCM3}

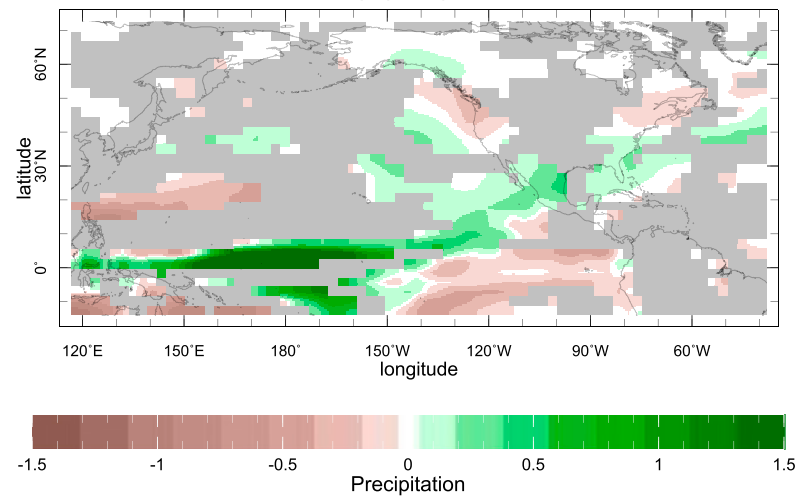

FIG. 12. The regression of ensemble mean precipitation on the principal components from Fig. 11. Values are only shown where significant at the $90 \%$ level. Units: Height (m), SST (K), and per standard deviation of the PC $\left(\mathrm{mm} \mathrm{day}^{-1}\right)$.

rotated mode for CCM3) plotting values where significant at the $90 \%$ level (which was chosen so as to better see the large-scale pattern of precipitation teleconnection). As expected there is an increase in precipitation over the warm SST anomaly in the western equatorial Pacific Ocean, and a decrease over the central to eastern equatorial Pacific Ocean. In all the models there are dry anomalies at the west coast of North America, although 
the latitudinal reach of this varies and does not always incorporate California.

These results quite strongly indicate that the west coast ridge pattern of winter 2013/14 was to some extent forced by the tropical Pacific SST anomalies of the past winter. These SST anomalies cause precipitation and, hence, atmospheric heating anomalies above them, which can force Rossby waves that propagate toward North America, creating a ridge and depressed precipitation there. However, returning to the analysis of the simulations of the past winters, it should be noted that the height anomalies at the west coast are weaker than those observed. Therefore, despite the importance of this third (or fourth in CCM3) mode of SST-forced variability, internal atmospheric variability also likely played a role that worked constructively with the SST-forced component to create the observed anomaly magnitude.

\section{How well can the history of California winter precipitation be reproduced by SST-forced models?}

The hopes raised in the previous two sections that there may be some opportunity to forecast, in general, California winter precipitation in terms of slowly evolving SSTs is confirmed somewhat by examination of Fig. 13. Here we show a comparison of observed and modeled time histories of all-California winter precipitation. The comparison is shown for the entire time periods available for the models that overlap with observations and hence covers, for two models, 1895-2014. The plot shows the ensemble mean, which closely isolates the SST-forced component common to all ensemble members, and the plus and minus two standard deviation spread of the model ensembles about their respective means. The correlation coefficient between the ensemble mean and the observations is noted on the plots. From these comparisons it is clear that the ability of models to simulate the past history of precipitation varies considerably. At the high end, the ESRL GFSv2 suggests almost a third of the precipitation variance is SSTforced, although this is only for the post-1979 period, while, at the low end, CCM3 suggests the value is only a few percent, although that is for the entire post- 1895 period. Despite the success of some models in this regard, notably, all of the models failed to simulate a drought in the late 1980s to early 1990s, four of four failed to simulate the mid-1970s drought, and two of two failed to simulate the general dry period in the 1920 s to early 1930s. These results are consistent with the observational analyses (section 5) that showed the typical cause of California dry winters being internal atmospheric variability. Also consistent, the models seem to have some success in simulating wet winters during El
Niño events, for example, 1982/83 and 1941/42. The results are also consistent with the recent drought, which is moderately reproducible in terms of SST forcing, being a quite unusual event. Interestingly, the correlation between the model ensemble means and observations was higher (although not necessarily more statistically significant) in the post-1979 period than in the complete period for those simulations that began prior to 1979 . Further work will be required to determine if this genuinely represents a tighter correlation between California precipitation and SSTs in recent decades or if it is the result of improvements in SST monitoring.

The models also capture the decadal-scale drop in precipitation since about the late 1970s. Quantitatively, this is shown in the box-and-whisker plot in Fig. 10, where observed and modeled 1979-2014 trends, expressed as a departure from the 1979-2014 mean (i.e., final minus first value of the linear trend divided by two), are shown as green crosses and stars. The two trends are almost identical. Also clear is that the decadal trend accounts for relatively little of the amplitude of the 2011-14 drought but much, and sometimes all, the modeled drought amplitude. The post- to late-1970s drying trend is thought to be related to the 1997/98 decadal shift in the Pacific Ocean to more La Niña-like conditions, and previous studies have shown how this generated a dry shift across southwestern North America (Huang et al. 2005; Hoerling et al. 2010; Seager and Vecchi 2010; Seager and Naik 2012).

\section{Temperature anomalies during the 2011-14 California drought}

By increasing atmospheric evaporative demand, high temperatures intensify droughts beyond that caused by precipitation decreases alone (Weiss et al. 2009). Figure 14 shows the time history of all California winter half-year (November-April) temperature from the Climate Division data. Winter 2013/14 was the warmest on record while the two previous winters were not anomalously warm compared to averages for the last three decades. There has also been a warming of over $1^{\circ} \mathrm{C}$ since the late nineteenth century, which accounts for about onethird of the extreme warm anomaly in the past winter. While at least some part of this warming trend is likely due to rising GHGs, Johnstone and Mantua (2014) argue that much can be accounted for by a strong shift in the latter part of the twentieth century to low sea level pressure over the northeastern Pacific that they attribute to natural variability. As shown in the model analysis of Seager and Hoerling (2014), the GHG-driven warming is forcing a widespread tendency for a decline in soil moisture across western North America. Figure 14 also shows maps of 

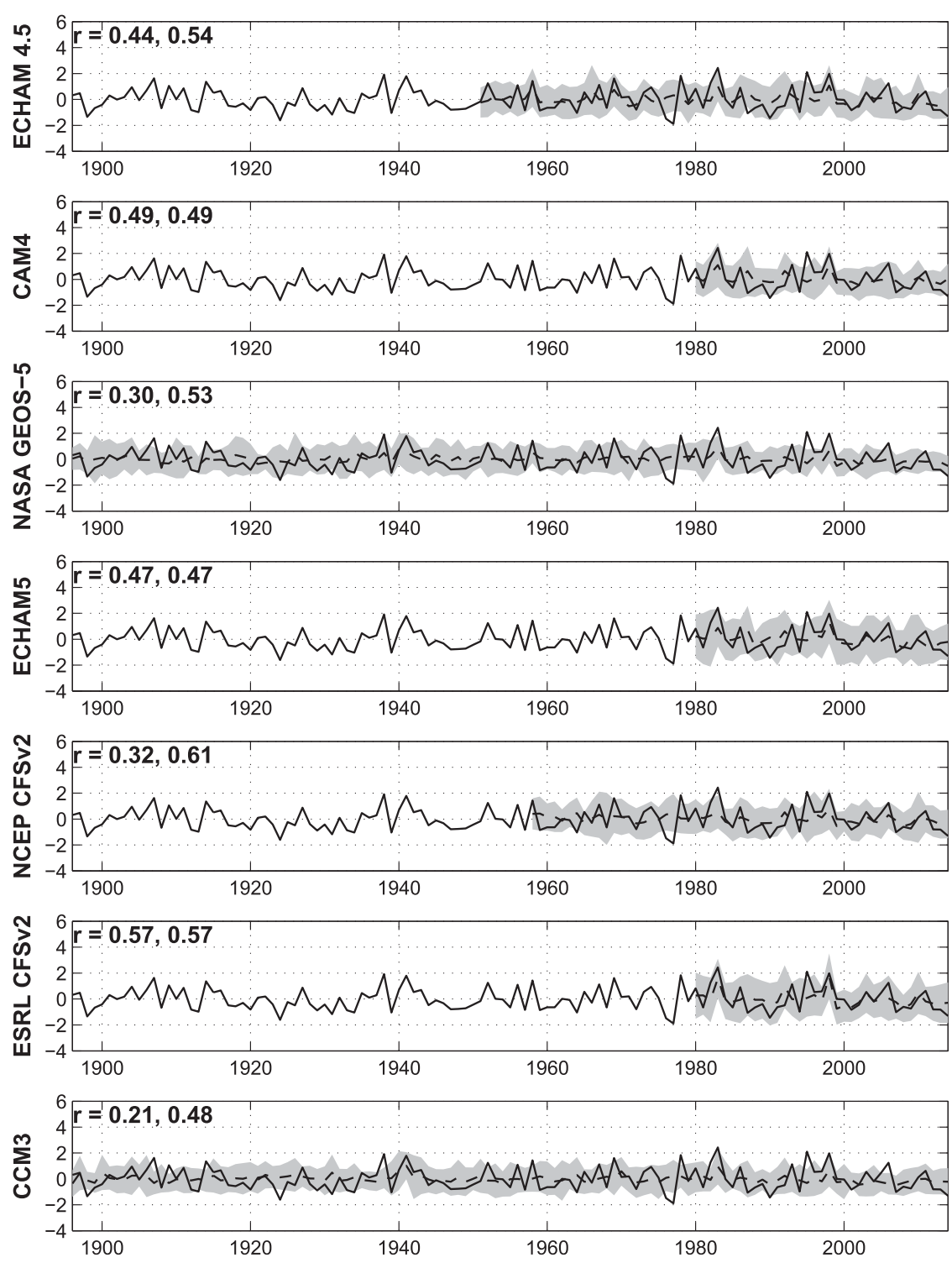

FIG. 13. Time histories of observed and modeled all-California winter precipitation $\left(\mathrm{mm} \mathrm{day}^{-1}\right)$. The ensemble mean for each model is shown together with the plus and minus two standard deviation spread of the model ensemble about its ensemble mean. Correlation coefficients between ensemble mean and observations for each model are noted in the top-left corner of each panel, with the first value being for the entire modeled period and the second value being for the 1979-2014 period common to all simulations.

surface temperature and surface pressure anomalies for the past three winters taken from the NCEP-NCAR reanalysis. The temperature anomalies were modest at the west coast of North America in winters 2011/12 and 2012/13. In contrast, there was a striking localized warm anomaly in southwestern North America and over the eastern North Pacific in winter 2013/14. The surface pressure anomaly makes it clear that the intensity of these warm anomalies is related to the high pressure system with warm southwesterly flow into California (which will also be descending) and over the northeastern Pacific, that is, the same pattern of atmosphere-ocean variability that caused the decrease in precipitation. To check the importance of the temperature anomalies, we examined the NOAA Climate Division Palmer drought severity index (PDSI; available at http://iridl.ldeo.columbia.edu/expert/ SOURCES/.NOAA/.NCDC/.CIRS/.nClimDiv/.v1/.pdsi/). While winter 2013/14 was only the sixth driest since 1895, it has the most negative PDSI value, indicating the incremental impact of temperature. This is consistent with 
a) CA Temperature

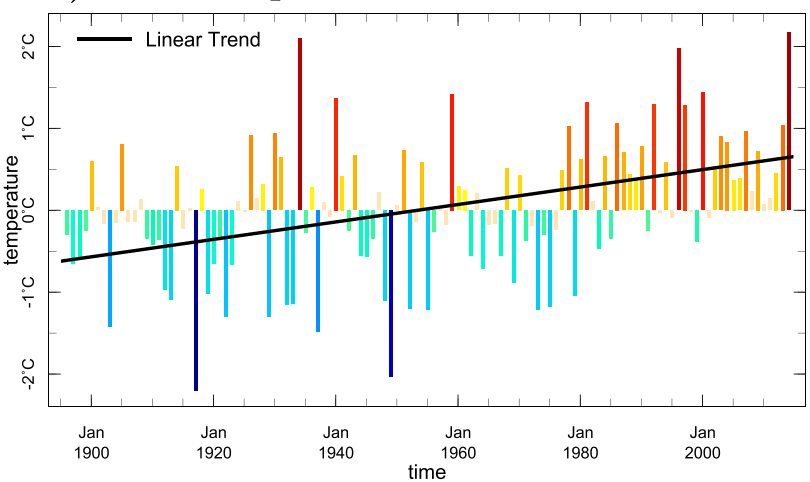

c) $2012-2013$

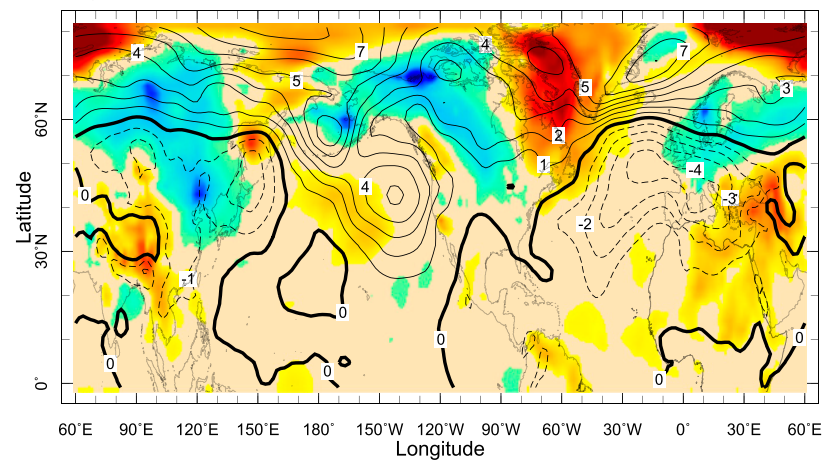

b) 2011-2012

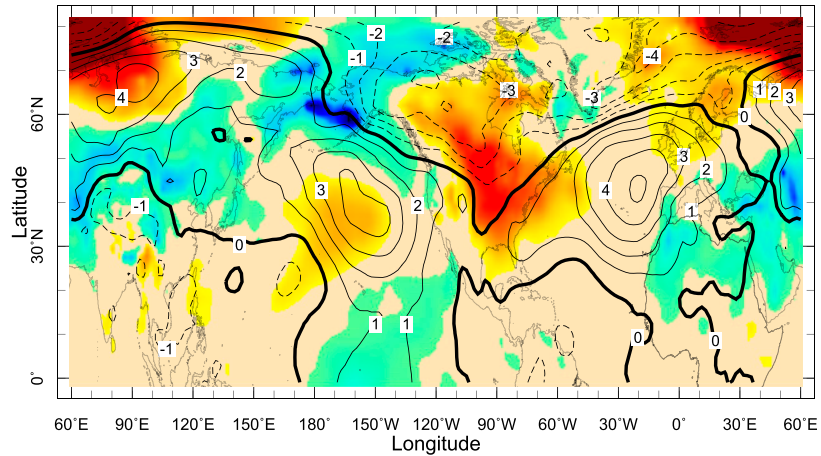

d) 2013-2014

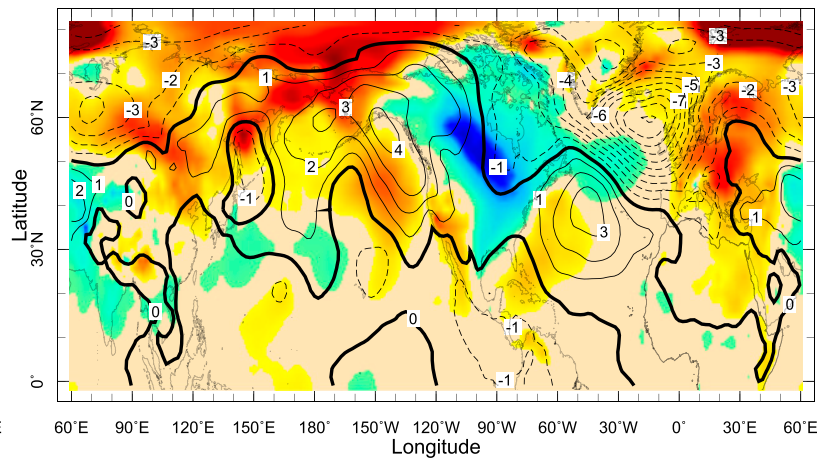

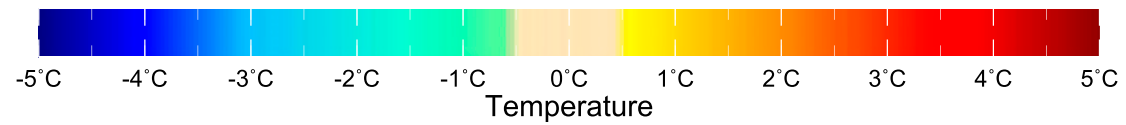

FIG. 14. (a) The time history of all-California November-April temperature with the linear trend added. Also shown are the NovemberApril anomalies of surface air temperature $\left({ }^{\circ} \mathrm{C}\right.$ ) and surface pressure (mb) for the winters of (b) 2011/12, (c) 2012/13, and (d) 2013/14.

the combined instrumental and tree ring analysis of Griffin and Anchukaitis (2014) and the conclusion of Diffenbaugh et al. (2015) that rising temperatures have been increasing drought risk in California. However, it should be noted that the NOAA PDSI calculation uses the Thornthwaite temperature-dependent method for computing potential evapotranspiration (PET), which can overstate the impact of warming on land surface moisture loss (Hoerling et al. 2012). An assessment of PDSI using the more physical net radiation-based Penman-Monteith method (Cook et al. 2014) and multiple climate datasets shows that approximately two-thirds to three-quarters of the 3-yr summer average (2012-14) PDSI depression was driven by the precipitation reduction and one-quarter to one-third by increasing PET, with between one-quarter and three-quarters of the latter due to the long-term warming trend (Williams et al. 2015). Cheng et al. (2015, manuscript submitted to J. Climate), in a model-based study of California soil moisture, found that the rise of GHGs from preindustrial values to current levels led to increased drought risk (as PET increase overwhelmed modeled precipitation increase) when using a metric of upper soil moisture but to reduced risk when considering a metric of 1-m depth soil moisture.

\section{Assessing human-induced climate change contribution to the 2011-14 California drought}

It is reasonable to ask whether human-driven precipitation change has played a role in the drought given that models project southwestern North America as a whole to become more arid as a result of rising GHGs (Seager et al. 2007, 2013; Maloney et al. 2014). Determining human-induced climate change from the observational record is difficult. Across North America there is strong interannual to decadal and multidecadal variability of precipitation, which means that observed trends, even over very long time periods, could arise from natural variability. For example, in the case of southwestern North America as a whole, the last century 

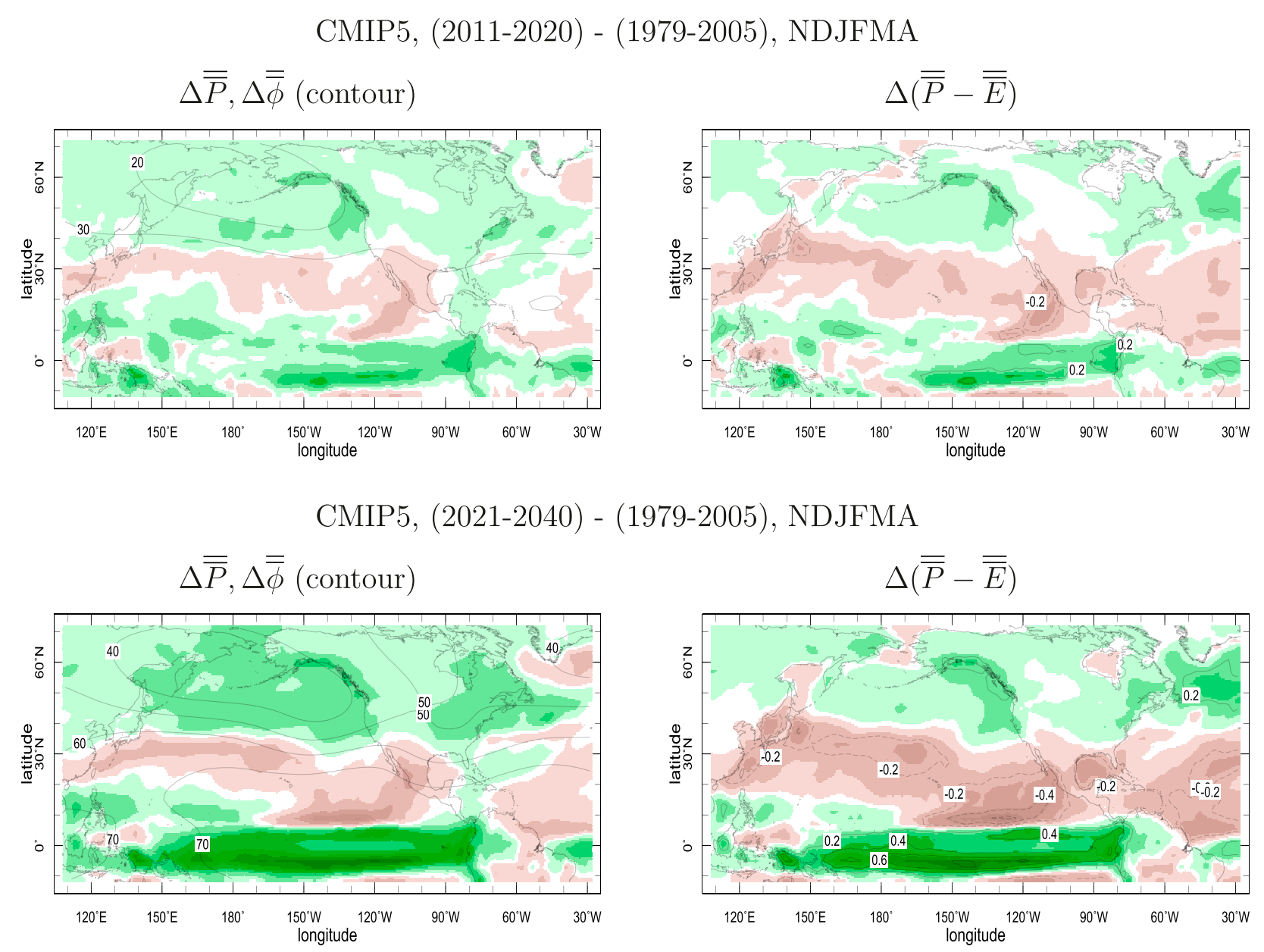

- (1979-2005), NDJFMA
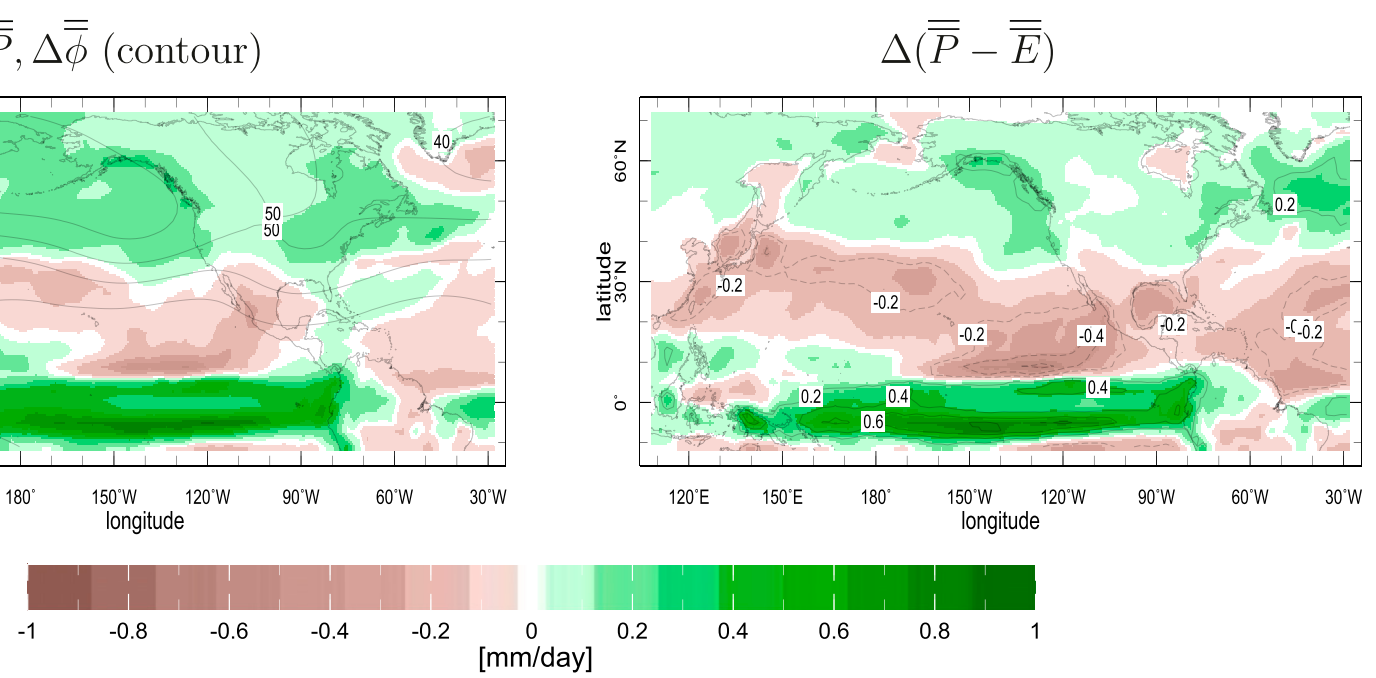

FIG. 15. The CMIP5 38-model mean of the (top) 2011-20 and (bottom) 2021-40 minus 1979-2005 (left) change in precipitation $\overline{\bar{P}}$ and (right) precipitation minus surface evaporation/evapotranspiration $\overline{\bar{P}}-\overline{\bar{E}}$, where the double overbar indicates the climatological monthly mean as in Seager et al. (2014b). Also shown in (left) are the changes in 200-mb height. All results are for the November-April winter half year using the RCP8.5 emissions scenario. Units: Precipitation $P$ and $P-E\left(\mathrm{~mm} \mathrm{day}^{-1}\right)$ and height $(\mathrm{m})$.

exhibited a striking pluvial in the first two decades (Cook et al. 2011), serious drought in the 1930s and 1950s, and another pluvial in its last two decades (Seager et al. 2005; Huang et al. 2005; Swetnam and Betancourt 1998), followed by drought since (Weiss et al. 2009; Cayan et al. 2010). Precipitation trends computed amidst such a rich record are most likely heavily influenced by natural variability (e.g., Hoerling et al. 2010; Seager and Vecchi 2010).

Climate model projections provide a different way of estimating human-induced climate change. Averaging across an ensemble of radiatively forced coupled climate models isolates the common component forced by rising GHGs, variations in ozone, solar variability, volcanism, aerosols, etc. Here we use the CMIP5 archive for which Seager and Hoerling (2014) show that modeled human-induced precipitation changes to date across North America are small compared to natural interannual variability. Here we show the 38-model-mean projected changes in precipitation $P$ and precipitation minus evaporation $(P-E)$ for the November-April half year for the years of 2011-20 and 2021-40 minus 1961-2000 using the RCP8.5 emissions scenario (Fig. 15, model data are available at http://kage. ldeo.columbia.edu:81/SOURCES/.LDEO/.ClimateGroup/. PROJECTS/.IPCC/.CMIP5/.MultiModelMeans/.MMM-v2/). For both the current decade and the next two decade periods, there is a widespread area of subtropical drying as measured by a reduction of $P$ and a stronger reduction of $P-E$, which dries Mexico and parts of Arizona, New Mexico, and Texas. This pattern is consistent with expectations of hydroclimate change due to rising GHGs 
(Seager et al. 2014b). For the current decade, this drying area includes California but is very weak. The multimodel mean and median are -0.01 and $-0.03 \mathrm{~mm} \mathrm{day}^{-1}$, more than an order of magnitude smaller than the precipitation drops during the 2011-14 drought winters. For the future period, central and Northern California is projected to have an increase in winter half-year $P$ and a slightly smaller increase in $P-E$ (as warming increases winter $E$ ). The change in California is made up of an increase in midwinter $P$ but a decrease in spring that connects with the interior southwest drying (Neelin et al. 2013; Pierce et al. 2013; Gao et al. 2014). The slight drying in the current decade arises because the spring drying proceeds faster than the midwinter wetting. Hence, for California, the models project an emerging shorter, sharper, wet season. Given that the recent California drought included precipitation drops in midwinter as well as spring, it is not consistent with the model-projected human-driven mean climate change signal. Figure 14 also shows the change in 200-mb heights. While the heights increase everywhere because of the warming troposphere, the climate change signal also includes a trough off the west coast with a southward-shifted jet stream (Neelin et al. 2013; Simpson et al. 2014; Seager et al. 2014b). This is consistent with winter wetting in central to Northern California, as also seen in IPCC (2013). The circulation anomalies during the recent California drought are therefore also not consistent with model projections of human-driven mean circulation anomalies. The radiatively forced reduction in precipitation for the current decade is well under an order of magnitude smaller than the anomalies that occurred in California in the recent drought and is also smaller than the drying forced by SST anomalies. The projected future winter half-year wetting in central to Northern California is similarly small (on the order of $0.1 \mathrm{~mm} \mathrm{day}^{-1}$ ), but made up of larger early winter half-year wetting and late winter half-year drying changes.

\section{Conclusions and discussion}

The depleted state of water supply available to municipalities and agriculture in California in 2014 arose from a major, if not record-breaking, meteorological drought. The three-winter average precipitation from 2011/12 to 2013/14 was the second-lowest three-winter precipitation deficit on record (behind 1974-77). Here we have attempted to determine the causes of this drought, examining the roles of atmospheric variability, forcing from SST anomalies, and possible human-induced climate change. We have also attempted to place the recent drought in the context of what generally causes dry California winters and the long-term record of California hydroclimate.

\section{a. Conclusions}

- The current drought, although extreme, is not outside the range of California hydroclimate variability, and similar events have occurred before. Although there has been a drying trend in California since the late 1970s, when considering the full observational record since 1895 , there is no appreciable trend to either wetter or drier California winters. California has experienced a warming trend over this period of about $1^{\circ} \mathrm{C}$.

- In general, dry California winters are caused by a ridge immediately off the west coast that appears as part of a midlatitude wave train with no obvious forcing from the ocean either in the midlatitudes or the tropics. In contrast, wet California winters tend to occur during El Niño events and with a trough over the eastern North Pacific Ocean. The association with El Niño is not strong and not all wet California winters are during El Niños: the serious California drought of 1976/77 occurred during an El Niño event.

- Despite the general role of internal atmosphere variability in driving dry California winters, the probability for occurrence of three consecutive dry winters for statewide California precipitation during 2011-14 was significantly increased by the influence of varying SSTs. This is evidenced by the fact that all seven SST-forced models examined produced dry west coast winters when forced with the observed SST anomalies. Winter 2011/12 was a case of forcing from a La Niña event. In contrast, the winters of 2012/ 13 and 2013/14 appear to have been forced, significantly, by a different pattern of tropical Pacific SST anomalies, with warm in the west and weak cool in the east. In response to these SST anomalies, the models produce precipitation anomalies and a wave train that arches northeastward from the tropical western Pacific to North America and has a ridge and reduced precipitation over the west coast, including California. In addition, the late 1990s shift to more La Niña-like conditions in the Pacific Ocean has created a decadal drying trend that is well reproduced by the models and accounts for a small portion of the observed drought and a much larger portion of the modeled droughts.

- As such, evidence for potential seasonal-to-interannual predictability of the recent California drought was found based on the climate model analysis. The potential predictability was highest during the 2011/ 12 winter when La Niña conditions prevailed, although considerable potential predictability was also identified during the subsequent two ENSO-neutral winters. This predictability is, however, "potential" as it requires the important aspects of the SST 
variability to itself be predictable, which was not investigated here.

- The tropical SST forced wave train-west coast ridge pattern contributing to dry California conditions during the past two winters is not unique to just these years but appears throughout the historical simulation period of all the models (after ENSO and Pacific decadal variability) as an EOF of the ensemble mean, that is, of the ocean-forced component of atmospheric variability. However, this mode explains relatively little of the total variability, and its leading role in the past two winters is unusual since it is more likely to co-occur with, and be obscured by, the more leading modes.

- For the 3-yr period 2011-14, based on the model simulations, the cumulative deficit of California precipitation cannot be explained by SST forcing alone, suggesting an additional contribution from internal atmospheric variability. Our diagnosis of over 150 realizations of model simulations indicates less than half of the drought intensity resulted from potentially predictable SST forcing, while more than half was related to internal atmospheric variability unpredictable at long leads, although this estimated fraction is subject to error because of incorrect model sensitivity to SST forcing.

- More generally, examining the entire available histories of overlapping observations and model simulations, there is a strong indication that up to a third of the variance of California winter precipitation variance is driven by SST anomalies. This skill in hindcasting California precipitation is nonetheless highly model dependent, with some models having essentially zero skill. Further, for the past three winters the models seemed better able to capture the amplitude of the west coast ridge than the associated California precipitation reduction. Additional research is required to determine the full extent of the SST-forced component of California precipitation variability, its links to circulation variability, and its capability to predict the driving SST anomalies.

- Diagnosis of CMIP5 models indicates human-induced climate change will increase California precipitation in midwinter, associated with an increase in westerly flow entering the central Pacific west coast and a lowpressure anomaly over the North Pacific. However, for the current decade the projections indicate a weak drying that arises from drying in the later part of the winter half year that is greater than wetting in the earlier part. This radiatively forced signal is more than an order of magnitude smaller than the observed 3-yr average anomaly. The recent severe all-winter rainfall deficit is thus not a harbinger of future precipitation change. Human-driven climate change will primarily impact California hydroclimate via continued warming, causing more precipitation to fall as rain instead of snow and stressing surface moisture via increases in potential evapotranspiration.

While we have appealed to tropical Pacific teleconnections as contributing factors for the California drought of the past three winters, it must be emphasized that causal attribution to particular regional features of SST forcing remains to be completed. Two of the contributing institutions (NASA GSFC and LDEO) have performed simulations of the past winters with SST anomalies restricted to various oceans and subbasins. These do support the idea that tropical Pacific SST anomalies were key but also find responses to SST anomalies elsewhere. One contributing institution (NOAA ESRL) has done experiments that isolated the response to sea ice changes and found little in terms of precipitation response over California. These results are preliminary, and more careful and targeted modeling studies are needed to determine the exact nature and origin of the ocean forcing of the PacificNorth America circulation anomalies that contributed to the California drought of past winters.

\section{b. Discussion}

\section{1) Predictability}

The retrospective climate simulations imply that seasonal forecasts could have skillfully anticipated California drought conditions for the past three winters. After all, the SST anomalies of the past three winters led to dry winters in all seven models when run in hindcast mode. However, that would have required predicting the relevant SST anomalies. Although we refrain from showing it here, examination of the SST forecasts initialized in October performed for the North American Multimodel Ensemble (NMME) using coupled models, and performed by the IRI using a combination of SSTonly prediction methods, shows that the La Niña of 2011/12 was predicted and that both systems predicted the warm tropical western Pacific in winters 2012/12 and 2013/14, although the IRI with greater strength. Consistently, the NMME models predicted drier than normal conditions in California for 2011/12 and 2012/13 and the IRI for all three winters. Again, consistently, the Climate Prediction Center seasonal outlook for winter 2011/12 predicted drier-than-normal conditions, and the outlook for the next two winters was also for modestly below normal precipitation. The observed precipitation reductions were, of course, much greater. However, it should be recalled that in order for an SST-based prediction to be considered worthy of release to the public, it must be based on a well-established, understood, and proven relationship between SST anomalies and the 
circulation and precipitation. This was not, in general, the case for the past three winters in California. Seasonal forecast skill for California is limited, consistent with the important role for internal atmospheric variability in driving dry winters found here. Further, the mode of ocean-forced variability found here explains relatively little of the total variance and can easily be overwhelmed by other modes of ocean-forced or internal atmospheric variability.

\section{2) UNANSWERED QUESTIONS AND DIRECTIONS FOR FUTURE RESEARCH}

Our multimodel ensemble suggests that up to a third of California winter precipitation variance is SST-forced but that the ability of models to reproduce this is highly variable. This requires a serious effort to better understand the SST-forcing that is important for California, the physical mechanisms that link California precipitation to SST and circulation variations, and how the representation of these vary by model and why. We have emphasized the role of Pacific SST anomalies here, but future work should address the possibility of SST anomalies in other ocean basins also playing a role. This work is critical and could lead to an important improvement in the skill of seasonal precipitation forecasts for California. More specifically, now that this droughtinducing mode of SST-forcing has been identified, forecasters should be on the lookout for similar SST patterns in the future and pay close attention to model predictions when they occur because the potential for improving seasonal prediction for the west coast is clearly there.

Our conclusion that the drought was caused by natural variability and not human-induced climate change is in part based on the CMIP5 models that project wetter conditions in central to Northern California in winter but drier conditions in spring. The midwinter wet signal is consistent with a wet-get-wetter, dry-get-drier hydroclimate response because, after all, most of California experiences a wet climate in winter. The moisture budget analysis of Seager et al. (2014b) confirms that rising humidity combining with the climatological mean circulation is a major driver of wetting in California in winter. However, this is aided by a circulation response that causes a shift to more southwesterly mean winds striking the west coast in winter. This occurs despite a poleward shift of the storm track over the eastern North Pacific and west coast and is related to a local southward shift of the jet stream (Neelin et al. 2013; Simpson et al. 2014; Seager et al. 2014b). The mean flow shift is part of a fairly high zonal wavenumber response to radiative forcing that stretches across the Pacific from Asia and the western Pacific and is surprisingly robust across models (Simpson et al. 2014; Seager et al. 2014b), but so far unexplained in the literature.

The other point of faith in the model projections is that they correctly represent the radiatively forced SST change. The long-term change seen in observations over the past few decades is associated with the second EOF mode of 200-mb heights and also has a ridge at the west coast and drying. We have suggested that this apparent trend is actually Pacific decadal variability based on the similarity of its SST pattern, with broad cooling centered in the central to eastern tropical Pacific and surrounding warming in a horseshoe shape, to that identified as a natural decadal mode of variability by Zhang et al. (1997), Deser et al. (2004), and many others. In contrast to this pattern, the CMIP5 models have a quite uniform SST response to radiative forcing with a modest maximum in the central and eastern equatorial Pacific Ocean. However, nature has deviated steadfastly from such an SST trend and, when looked at even over a century or more, the observed SST trend is toward an increased, not decreased, east-west gradient (Karnauskas et al. 2009; Solomon and Newman 2012). The observed trend to an increasing gradient could be the result of natural multidecadal-to-centennial time-scale variability (Zhang et al. 1997; Karnauskas et al. 2012). On the other hand, it has been postulated that increased radiative forcing could force a stronger east-west gradient (Clement et al. 1996), in contrast to the CMIP5 model results. Either way, it should be noted that the warm western-cool eastern tropical Pacific SST anomaly that was key to forcing the recent California drought worked via changing gradients of SSTs that reorganized tropical convection. Warming in the western tropical Pacific region (due to rising GHGs, for example) would likely not have the same effect if it was part of a more spatially uniform warming. Hence, in the same way we must better understand the model wave response to rising GHGs that helps make California wetter in midwinter in model projections, the spatial pattern of SST response also needs to be better understood, such that long-term changes due to natural variability and radiative forcing can be isolated.

Acknowledgments. This work was initiated by the NOAA Drought Task Force, and we thank Annarita Mariotti and Dan Barrie for organizational efforts and encouragement. We also thank Tom Delworth, Dan Cayan, Kelly Redmond, and an anonymous reviewer for their very valuable comments and criticisms on the NOAA report that was the basis for this paper. R.S., N.H., and J.N. were supported by NSF Awards AGS-1401400 and AGS-1243204 and NOAA Awards NA10OAR4310137 (Global Decadal Hydroclimate Variability and Change) and NA14OAR4310232. We thank Haibo Liu for 
assembling at LDEO the CMIP5 data for analysis. We thank two reviewers plus Tony Broccoli for their excellent and insightful reviews of the manuscript.

\section{REFERENCES}

Amos, C. B., P. Audet, W. C. Hammond, R. Burgman, I. A. Johanson, and G. Blewitt, 2014: Uplift and seismicity driven by groundwater depletion in central California. Nature, 509, 483-486, doi:10.1038/nature13275.

Bond, N. E., M. F. Cronin, H. Freeland, and N. Mantua, 2015: Causes and impacts of the 2014 warm anomaly in the NE Pacific. Geophys. Res. Lett., 42, 3414-3420, doi:10.1002/2015GL063306.

Borsa, A. A., D. C. Agnew, and D. R. Cayan, 2014: Ongoing drought-induced uplift in the western United States. Science, 345, 1587-1590, doi:10.1126/science.1260279.

California Department of Water Resources, 2015: Storage in major reservoirs. Accessed 25 June 2015. [Available online at http:// cdec.water.ca.gov/cgi-progs/reservoirs/STORAGE.]

Cayan, D., T. Das, D. Pierce, T. Barnett, M. Tyree, and A. Gershunova, 2010: Future dryness in the southwest United States and the hydrology of the early 21 st century drought. Proc. Natl. Acad. Sci. USA, 107, 21 271-21 276, doi:10.1073/pnas.0912391107.

Cheng, L., M. Hoerling, A. AghaKouchak, B. Livneh, X.-W. Quan, and J. Eischeid, 2015: How has human-induced climate change affected California drought risk? J. Climate, submitted.

Clement, A. C., R. Seager, M. A. Cane, and S. E. Zebiak, 1996: An ocean dynamical thermostat. J. Climate, 9, 2190-2196, doi:10.1175/ 1520-0442(1996)009<2190:AODT>2.0.CO;2.

Cook, B., R. Seager, and R. Miller, 2011: On the causes and dynamics of the early 20th century North American pluvial. J. Climate, 24, 5043-5060, doi:10.1175/2011JCLI4201.1.

_ J. E. Smerdon, R. Seager, and S. Coats, 2014: Global warming and 21st century drying. Climate Dyn., 43, 2607-2627, doi:10.1007/ s00382-014-2075-y.

Davis, R. E., 1976: Predictability of sea surface temperature and sea level pressure anomalies over North Pacific Ocean. J. Phys. Oceanogr., 6, 249-266, doi:10.1175/1520-0485(1976)006<0249: POSSTA $>2.0 . \mathrm{CO} ; 2$.

Deser, C., A. S. Phillips, and J. W. Hurrell, 2004: Pacific interdecadal climate variability: Linkages between the tropics and the North Pacific during boreal winter since 1900. J. Climate, 17, 3109-3124, doi:10.1175/1520-0442(2004)017<3109:PICVLB > 2.0.CO;2.

Diffenbaugh, N. S., D. L. Swain, and D. Touma, 2015: Anthropogenic warming has increased drought risk in California. Proc. Natl. Acad. Sci. USA, 112, 3931-3936, doi:10.1073/pnas.1422385112.

Famiglietti, J. S., and M. Rodell, 2013: Water in the balance. Science, 340, 1300-1301, doi:10.1126/science. 1236460.

Funk, C., A. Hoell, and D. Stone, 2014: Examining the contribution of the observed global warming trend to the California droughts of 2012/13 and 2013/14 [in "Explaining Extremes of 2013 from a Climate Perspective"]. Bull. Amer. Meteor. Soc., 95 (9), S11-S15, doi:10.1175/1520-0477-95.9.S1.1.

Gao, Y., L. R. Leung, J. Lu, Y. Liu, M. Huang, and Y. Qian, 2014: Robust spring drying in the southwestern U.S. and seasonal migration of wet/dry patterns in a warmer climate. Geophys. Res. Lett., 41, 1745-1751, doi:10.1002/2014GL059562.

Griffin, D., and K. Anchukaitis, 2014: How unusual is the 20122014 California drought? Geophys. Res. Lett., 41, 9017-9023, doi:10.1002/2014GL062433.

Hartmann, D. L., 2015: Pacific sea surface temperature and the winter of 2014. Geophys. Res. Lett., 42, 1894-1902, doi:10.1002/ 2015GL063083.
Haston, L., and J. Michaelsen, 1994: Long-term central coastal California precipitation variability and relationships to $\mathrm{El} \mathrm{Niño-}$ Southern Oscillation. J. Climate, 7, 1373-1387, doi:10.1175/ 1520-0442(1994)007<1373:LTCCCP>2.0.CO;2.

Herring, S. C., M. P. Hoerling, T. C. Peterson, and P. A. Stott, 2014: Explaining extreme events of 2013 from a climate perspective. Bull. Amer. Meteor. Soc., 95, S1-S96, doi:10.1175/ 1520-0477-95.9.S1.1.

Hoerling, M. P., and A. Kumar, 2002: Atmospheric response patterns associated with tropical forcing. J. Climate, 15, 2184-2203, doi:10.1175/1520-0442(2002)015<2184:ARPAWT>2.0.CO;2.

_ — - and T. Xu, 1997: El Niño, La Niña, and the nonlinearity of their teleconnections. J. Climate, 10, 1769-1786, doi:10.1175/ 1520-0442(1997)010<1769:ENOLNA $>2.0 . C O ; 2$.

,$- \ldots$, and,- 2001 : Robustness of the nonlinear climate response to ENSO's extreme phases. J. Climate, 14, 1277-1293, doi:10.1175/1520-0442(2001)014<1277:ROTNCR > 2.0.CO;2.

_ , J. Eischeid, and J. Perlwitz, 2010: Regional precipitation trends: Distinguishing natural variability from anthropogenic forcing. J. Climate, 23, 2131-2145, doi:10.1175/2009JCLI3420.1. X. Quan, H. Diaz, R. Webb, R. Dole, and D. Easterling, 2012: Is a transition to semi-permanent drought conditions imminent in the U.S. Great Plains? J. Climate, 25, 8380-8386, doi:10.1175/JCLI-D-12-00449.1.

,-- - A. Kumar, R. Leung, A. Mariotti, K. Mo, S. Schubert, and R. Seager, 2014: Causes and predictability of the 2012 Great Plains drought. Bull. Amer. Meteor. Soc., 95, 269-282, doi:10.1175/BAMS-D-13-00055.1.

Howitt, R. E., J. Medellin-Azuara, D. MacEwan, J. R. Lund, and D. A. Summer, 2014: Economic analysis of the 2014 drought for California agriculture. Tech. Rep., Center for Watershed Sciences, University of California, Davis, 20 pp. [Available online at https://watershed.ucdavis.edu/files/content/news/Economic Impact_of_the_2014_California_Water_Drought.pdf.]

Huang, H., R. Seager, and Y. Kushnir, 2005: The 1976/77 transition in precipitation over the Americas and the influence of tropical SST. Climate Dyn., 24, 721-740, doi:10.1007/s00382-005-0015-6.

Hurrell, J. W., J. J. Hack, D. Shea, J. M. Caron, and J. Rosinski, 2008: A new sea surface temperature and sea ice boundary data set for the Community Atmosphere Model. J. Climate, 21, 5145-5153, doi:10.1175/2008JCLI2292.1.

IPCC, 2013: Climate Change 2013: The Physical Science Basis. Cambridge University Press, $1535 \mathrm{pp}$.

Johnstone, J. A., and N. J. Mantua, 2014: Atmospheric controls on northeast Pacific temperature variability and change, 1900-2012. Proc. Natl. Acad. Sci. USA, 111, 14360-14365, doi:10.1073/ pnas.1318371111.

Kalnay, E., and Coauthors, 1996: The NCEP/NCAR 40-Year Reanalysis Project. Bull. Amer. Meteor. Soc., 77, 437-471, doi:10.1175/ 1520-0477(1996)077<0437:TNYRP > 2.0.CO;2.

Kaplan, A., M. A. Cane, Y. Kushnir, A. C. Clement, M. B. Blumenthal, and B. Rajagopalan, 1998: Analyses of global sea surface temperature: 1856-1991. J. Geophys. Res., 103, 18 567-18 589, doi:10.1029/97JC01736.

Karnauskas, K. B., R. Seager, A. Kaplan, Y. Kushnir, and M. A. Cane, 2009: Observed strengthening of the zonal sea surface temperature gradient across the equatorial Pacific Ocean. J. Climate, 22, 4316-4321, doi:10.1175/2009JCLI2936.1.

_ - J. Smerdon, R. Seager, and J. F. Gonzalez-Rouco, 2012: A Pacific centennial oscillation predicted by coupled GCMs. J. Climate, 25, 5943-5961, doi:10.1175/JCLI-D-11-00421.1.

Kiehl, J. T., J. J. Hack, G. B. Bonan, B. A. Bovile, D. L. Williamson, and P. J. Rasch, 1998: The National Center for Atmospheric 
Research Community Climate Model: CCM3. J. Climate, 11, 11311149, doi:10.1175/1520-0442(1998)011<1131:TNCFAR > 2.0.CO;2.

Kistler, R., and Coauthors, 2001: The NCEP-NCAR 50-Year Reanalysis: Monthly means CD-ROM and documentation. Bull. Amer. Meteor. Soc., 82, 247-268, doi:10.1175/ 1520-0477(2001)082<0247:TNNYRM>2.3.CO;2.

Kumar, A., Q. Zhang, P. Peng, and B. Jha, 2005: SST-forced atmospheric variability in an atmospheric general circulation model. J. Climate, 18, 3953-3967, doi:10.1175/JCLI3483.1.

Lin, H., and J. Derome, 2004: Nonlinearity of the extratropical response to tropical forcing. J. Climate, 17, 2597-2608, doi:10.1175/1520-0442(2004)017<2597:NOTERT>2.0.CO;2.

Maloney, E. D., and Coauthors, 2014: North American climate in CMIP5 experiments. Part III: Assessment of 21st century projections. J. Climate, 27, 2230-2270, doi:10.1175/JCLI-D-13-00273.1.

Mason, S., and L. Goddard, 2001: Probabilistic precipitation anomalies associated with ENSO. Bull. Amer. Meteor. Soc., 82, 619-638, doi:10.1175/1520-0477(2001)082<0619:PPAAWE>2.3.CO;2.

Mirchi, A., K. Madani, M. Roos, and D. W. Watkins, 2013: Climate change impacts on California's water resources. Drought in Arid and Semi-Arid Regions, K. Schwabe et al., Eds., Springer, 301-319, doi:10.1007/978-94-007-6636-5_17.

Molod, A., L. Takacs, M. Suarez, J. Bacmeister, I. Somg, and A. Eichmann, 2012: The GEOS-5 Atmospheric General Circulation Model: Mean climate and development from MERRA to Fortuna. NASA Tech. Rep. TM-2012-104606, Vol.28,117 pp. [Available online at http://gmao.gsfc.nasa.gov/ pubs/docs/tm28.pdf.]

Neelin, J. D., B. Langenbrunner, J. E. Meyerson, A. Hall, and N. Berg, 2013: California winter precipitation change under global warming in the Coupled Model Intercomparison Project Phase 5 ensemble. J. Climate, 26, 6238-6256, doi:10.1175/ JCLI-D-12-00514.1.

Peng, P., and A. Kumar, 2005: A large ensemble analysis of the influence of tropical SSTs on seasonal atmospheric variability J. Climate, 18, 1068-1085, doi:10.1175/JCLI-3314.1.

Pierce, D. W., and Coauthors, 2013: Probabilistic estimates of future changes in California temperature and precipitation using statistical and dynamical downscaling. Climate Dyn., 40, 839856, doi:10.1007/s00382-012-1337-9.

Rayner, N., D. Parker, E. Horton, C. Folland, L. Alexander, D. Rowell, E. Kent, and A. Kaplan, 2003: Global analyses of sea surface temperature, sea ice, and night marine air temperature since the late nineteenth century. J. Geophys. Res., 108, 4407, doi:10.1029/2002JD002670.

Rienecker, M., and Coauthors, 2008: The GEOS-5 data assimilation system-Documentation of versions 5.0.1, 5.1.0, and 5.2.0. NASA Tech. Rep. TM-2008-104606, Vol. 27, 97 pp. [Available online at http://gmao.gsfc.nasa.gov/pubs/docs/Rienecker369.pdf.]

Roeckner, E. K., and Coauthors, 1996: The atmospheric general circulation model ECHAM-4: Model description and simulation of present day climate. Tech. Rep. 218, Max-Planck-Institut für Meteorologie, $90 \mathrm{pp}$.

— , and Coauthors, 2003: The atmospheric general circulation model ECHAM5: Part I: Model description. Tech. Rep. 349, Max-Planck-Institut für Meteorologie, $127 \mathrm{pp}$.

Ropelewski, C. F., and M. S. Halpert, 1986: North American precipitation and temperature patterns associated with the El Niño/Southern Oscillation. Mon. Wea. Rev., 114, 2352-2362, doi:10.1175/1520-0493(1986)114<2352:NAPATP >2.0.CO;2.

Scanlon, B. R., C. C. Faunt, L. Longuevergnce, R. C. Reedy, W. M. Alley, V. L. McGuire, and P. B. McMahon, 2012: Groundwater depletion and sustainability of irrigation in the US High
Plains and Central Valley. Proc. Natl. Acad. Sci. USA, 109, 9320-9325, doi:10.1073/pnas.1200311109.

Schubert, S. D., Y. Chang, M. J. Suarez, and P. J. Pegion, 2008: ENSO and wintertime extreme precipitation events over the contiguous United States. J. Climate, 21, 22-39, doi:10.1175/ 2007JCLI1705.1.

— , H. Wang, R. Koster, M. J. Suarez, and P. Groissman, 2014: Northern Eurasian heat waves and droughts. J. Climate, 27, 3169-3207, doi:10.1175/JCLI-D-13-00360.1.

Seager, R., 2007: The turn-of-the-century North American drought: Dynamics, global context and prior analogues. J. Climate, 20, 5527-5552, doi:10.1175/2007JCLI1529.1.

—- and G. A. Vecchi, 2010: Greenhouse warming and the 21st century hydroclimate of southwestern North America. Proc. Natl. Acad. Sci. USA, 107, 21 277-21 282, doi:10.1073/ pnas.0910856107.

—, and N. Naik, 2012: A mechanisms-based approach to detecting recent anthropogenic hydroclimate change. J. Climate, 25, 236-261, doi:10.1175/JCLI-D-11-00056.1.

- and M. P. Hoerling, 2014: Atmosphere and ocean origins of North American drought. J. Climate, 27, 4581-4606, doi:10.1175/ JCLI-D-13-00329.1.

Y. Kushnir, C. Herweijer, N. Naik, and J. Velez, 2005: Modeling of tropical forcing of persistent droughts and pluvials over western North America: 1856-2000. J. Climate, 18, 4065-4088, doi:10.1175/JCLI3522.1.

- - and Coauthors, 2007: Model projections of an imminent transition to a more arid climate in southwestern North America. Science, 316, 1181-1184, doi:10.1126/ science.1139601.

_ - M. Ting, C. Li, N. Naik, B. Cook, J. Nakamura, and H. Liu, 2013: Projections of declining surface-water availability for the southwestern United States. Nat. Climate Change, 3, 482-486, doi:10.1038/nclimate1787.

, L. Goddard, J. Nakamura, N. Naik, and D. Lee, 2014a: Dynamical causes of the 2010/11 Texas-northern Mexico drought. J. Hydrometeor., 15, 39-68, doi:10.1175/ JHM-D-13-024.1.

D. Neelin, I. Simpson, H. Liu, N. Henderson, T. Shaw, Y. Kushnir, and M. Ting, 2014b: Dynamical and thermodynamical causes of large-scale changes in the hydrological cycle over North America in response to global warming. J. Climate, 27, 7921-7948, doi:10.1175/JCLI-D-14-00153.1.

Simpson, I., T. Shaw, and R. Seager, 2014: A diagnosis of the seasonally and longitudinally varying mid-latitude circulation response to global warming. J. Atmos. Sci., 71, 2489-2515, doi:10.1175/ JAS-D-13-0325.1.

Smith, T. M., and R. W. Reynolds, 2004: Improved extended reconstruction of SST (1854-1997). J. Climate, 17, 2466-2477, doi:10.1175/1520-0442(2004)017<2466: IEROS $>2.0 . \mathrm{CO} ; 2$

Solomon, A., and M. Newman, 2012: Reconciling disparate twentieth-century Indo-Pacific ocean temperature trends in the instrumental record. Nat. Climate Change, 2, 691-699, doi:10.1038/nclimate 1591

Swain, D., M. Tsiang, M. Haughen, D. Singh, A. Charland, B. Rajarthan, and N. S. Diffenbaugh, 2014: The extraordinary California drought of 2013/14: Character, context and the role of climate change [in "Explaining Extremes of 2013 from a Climate Perspective']. Bull. Amer. Meteor. Soc., 95 (9), S3-S6, doi:10.1175/1520-0477-95.9.S1.1.

Swetnam, T. W., and J. L. Betancourt, 1998: Mesoscale disturbance and ecological response to decadal climate variability in the 
American southwest. J. Climate, 11, 3128-3147, doi:10.1175/ 1520-0442(1998)011<3128:MDAERT>2.0.CO;2.

Vano, J. A., and Coauthors, 2014: Understanding uncertainties in future Colorado River streamflow. Bull. Amer. Meteor. Soc., 95, 59-78, doi:10.1175/BAMS-D-12-00228.1.

Vose, R. S., S. Apllequist, I. Durre, M. J. Menne, C. N. Williams, C. Fenimore, K. Gleason, and D. Arndt, 2014: Improved historical temperature and precipitation time series for U.S. climate divisions. J. Appl. Meteor. Climatol., 53, 1232-1251, doi:10.1175/JAMC-D-13-0248.1.

Wang, H., and S. Schubert, 2014: Causes of the extreme dry conditions over California during early 2013 [in "Explaining Extremes of 2013 from a Climate Perspective"]. Bull. Amer. Meteor. Soc., 95 (9), S7S10, doi:10.1175/1520-0477-95.9.S1.1.

Weiss, J. L., C. L. Castro, and J. T. Overpeck, 2009: Distinguishing pronounced droughts in the southwestern United States:
Seasonality and effects of warmer temperatures. J. Climate, 22, 5918-5932, doi:10.1175/2009JCLI2905.1.

Williams, A. P., R. Seager, J. T. Abatzoglou, B. I. Cook, J. E. Smerdon, and E. R. Cook, 2015: Contribution of anthropogenic warming to California drought during 2012-2014. Geophys. Res. Lett., in press.

Wu, A., and W. W. Hsieh, 2004: The nonlinear Northern Hemisphere winter atmospheric response to ENSO. Geophys. Res. Lett., 31, L02203, doi:10.1029/2003GL018885.

Zhang, T., J. Perlwitz, and M. P. Hoerling, 2014: What is responsible for the strong observed asymmetry in teleconnections between El Niño and La Niña? Geophys. Res. Lett., 41, 1019-1025, doi:10.1002/2013GL058964.

Zhang, Y., J. M. Wallace, and D. S. Battisti, 1997: ENSO-like decadeto-century scale variability: 1900-93. J. Climate, 10, 1004-1020, doi:10.1175/1520-0442(1997)010<1004:ELIV>2.0.CO;2. 